\title{
REVIEW
}

\section{Dorzolamide/Timolol Fixed Combination: Learning from the Past and Looking Toward the Future}

\author{
Anastasios G. Konstas · Leopold Schmetterer • Andreas Katsanos • \\ Cindy M. L. Hutnik • Gábor Holló • Luciano Quaranta • \\ Miguel A. Teus · Hannu Uusitalo · Norbert Pfeiffer · L. Jay Katz
}

Received: August 25, 2020 / Accepted: October 3, 2020 / Published online: October 27, 2020

(C) The Author(s) 2020

\section{ABSTRACT}

The key clinical attributes of preserved dorzolamide/timolol fixed combination (DTFC) and the emerging potential of preservative-free (PF) DTFC are reviewed with published evidence and clinical experience. The indications and role of DTFC in current glaucoma management are

\author{
A. G. Konstas ( $\square)$ \\ 1st and 3rd University Departments of \\ Ophthalmology, Aristotle University of \\ Thessaloniki, Thessaloniki, Greece \\ e-mail: agkonstas@gmail.com \\ L. Schmetterer \\ Singapore Eye Research Institute, Singapore \\ National Eye Centre, Singapore, Singapore \\ L. Schmetterer \\ School of Chemical and Biomedical Engineering, \\ Nanyang Technological University, Singapore, \\ Singapore \\ L. Schmetterer \\ Ophthalmology and Visual Sciences Academic \\ Clinical Program, Duke-NUS Medical School, \\ Singapore, Singapore \\ L. Schmetterer \\ SERI-NTU Advanced Ocular Engineering (STANCE), \\ Singapore, Singapore \\ L. Schmetterer \\ Center for Medical Physics and Biomedical \\ Engineering, Medical University of Vienna, Vienna, \\ Austria
}

critically discussed. Preserved DTFC became the first intraocular pressure (IOP)-lowering fixed combination (FC) approved by the US Food and Drug Administration (FDA) and remains one of most commonly used medications worldwide. The pharmacological properties of DTFC reflect those of its two time-tested constituents, i.e., the carbonic anhydrase inhibitor dorzolamide and the non-selective beta-blocker timolol. In

\author{
L. Schmetterer \\ Department of Ophthalmology, Medical University \\ of Vienna, Vienna, Austria \\ L. Schmetterer \\ Institute of Ophthalmology, Basel, Switzerland
}

\section{A. Katsanos \\ Ophthalmology Department, University of Ioannina, Ioannina, Greece}

C. M. L. Hutnik

Ivey Institute of Ophthalmology and Western University, London, ON, Canada

\section{G. Holló}

Department of Ophthalmology, Semmelweis University, Budapest, Hungary

\section{Quaranta}

Department of Surgical and Clinical, Diagnostic and Pediatric Sciences, Section of Ophthalmology, University of Pavia-IRCCS Fondazione Policlinico San Matteo, Pavia, Italy

\section{A. Teus}

Ophthalmology Department, University of Alcalá, Alcalá de Henares, Madrid, Spain 
regulatory studies DTFC lowers IOP on average by $9 \mathrm{mmHg}(32.7 \%)$ at peak and by $7.7 \mathrm{mmHg}$ (27\%) at trough. In trials DTFC shows equivalence to unfixed concomitant therapy, but in real-life practice it may prove superior owing to enhanced convenience, elimination of the washout effect from the second drop, improved tolerability, and better adherence. PF DTFC became the first PF FC approved, first in unitdose pipettes, and more recently in a multidose format. Cumulative evidence has confirmed that PF DTFC is at least equivalent in efficacy to preserved DTFC and provides a tangible clinical benefit to patients with glaucoma suffering from ocular surface disease by improving tolerability and adherence. Finally, we identify areas that warrant further investigation with preserved and PF DTFC

Keywords: Benzalkonium chloride; Cosopt; Cosopt PF; Dorzolamide; Dorzolamide/timolol fixed combination; Glaucoma; Medical therapy; Ophthalmology; Preservative-free; Timolol

\section{Key Summary Points}

For 22 years preserved

dorzolamide/timolol fixed combination (DTFC) has been a successful and popular option employed to meaningfully reduce intraocular pressure (IOP).

H. Uusitalo

SILK, Department of Ophthalmology, Faculty of Medicine and Health Technology, Tampere University, Tampere, Finland

H. Uusitalo

Tays Eye Centre, Tampere University Hospital, Tampere, Finland

\section{N. Pfeiffer}

Department of Ophthalmology, University Medical Center of the Johannes Gutenberg-University

Mainz, Mainz, Germany

L. J. Katz

Glaucoma Research Center, Wills Eye Hospital, Philadelphia, PA, USA
In trials DTFC shows equivalence to unfixed concomitant therapy; in real-life practice, however, it may prove superior owing to enhanced convenience, elimination of the washout effect from the second drop, improved tolerability, and better adherence.

A significant body of evidence has confirmed that DTFC offers uniform day and night IOP control with a favorable safety profile for the vast majority of treated patients.

More evidence is needed on the transition to DTFC in patients insufficiently controlled with prostaglandin monotherapies and the precise role and timing of DTFC in the glaucoma treatment algorithm.

Cumulative evidence has confirmed that preservative-free (PF) DTFC is at least equivalent in efficacy to preserved DTFC and provides tangible clinical benefits to patients with glaucoma suffering from ocular surface disease (OSD) by improving tolerability and adherence.

In the future PF DTFC will further enhance its role in glaucoma therapy algorithms if controlled evidence demonstrates the long-term value of PF medications.

\section{DIGITAL FEATURES}

This article is published with digital features, including a summary slide, to facilitate understanding of the article. To view digital features for this article go to https://doi.org/10.6084/ m9.figshare.13034492

\section{INTRODUCTION}

Fixed combinations (FCs) of two, and recently three, intraocular pressure (IOP)-lowering medications have been formulated in order to attain a greater IOP reduction than that obtained by 
single agents, to allow fewer doses, to improve convenience, to reduce exposure to preservatives, and to optimize adherence [1-6]. In several systemic chronic diseases oral fixed-dose combinations simplify adjunctive medication regimens, improve adherence, reduce costs, decrease the rate of side effects, and improve clinical outcomes [7-10]. Poor adherence is considered the most important barrier for successful medical therapy $[8,11,12]$. Equally, in lifelong antiglaucoma therapy topical FCs may provide similar advantages [1, 10, 13-16].

Over the past 3 decades, FCs have increasingly become an established therapy in glaucoma principally owing to the success of the dorzolamide/timolol FC (DTFC, Cosopt ${ }^{\circledR}$ ) which was released commercially in the USA and in Europe in 1998 by Merck \& Co Inc (Whitehouse Station, NJ, USA) [17-22]. DTFC was the first IOP-lowering FC approved by the US Food and Drug Administration (FDA) and remains one of the few approved IOP-lowering FCs [5, 23-25]. In contrast, in Europe and other parts of the world several IOP-lowering FCs have been approved and launched [10, 16, 26]. Nevertheless, even after 22 years on the market DTFC remains one of the most successful IOPlowering medications worldwide. In 2019 DTFC was the first and fourth most used prescription medication in the European glaucoma and ophthalmic markets, respectively, with just under 1 billion standard units sold across 32 countries $(933,123,354)$ [27].

The pharmacology of DTFC is related to its two active ingredients (dorzolamide and timolol) and it is prescribed for twice daily dosing $[2,6,28]$. By consolidating these two different drugs into a single drop DTFC alleviated the daily drop-burden and encouraged patients with glaucoma to adhere to their therapy. As detailed later in this review, regulatory data has shown that DTFC lowers IOP by $9 \mathrm{mmHg}$ $(32.7 \%)$ at peak and by $7.7 \mathrm{mmHg}(27 \%)$ at trough [17-20, 29]. Importantly, DTFC approximated clinical equivalence to unfixed concomitant therapy with the largest $(0.7 \mathrm{mmHg})$, non-significant, difference versus unfixed therapy at 1600 hours $[20,21]$. In contrast, in reallife practice, DTFC and other glaucoma FCs have been shown to attain better IOP control compared with unfixed concomitant therapy [30-32] owing to enhanced convenience, elimination of the washout effect from the second drop, and improved adherence. The present review discusses briefly the regulatory evidence and then critically examines selected evidence related to preserved DTFC.

There is little evidence [33-35] concerning the role of FCs as initial therapy in glaucoma. In general medical practice, initial therapy with FCs has been found to provide an improved clinical outcome in the management of several chronic diseases $[36,37]$. The most ample evidence in ophthalmology is with DTFC as initial therapy to promptly lower unacceptably high IOP in the presence of significant damage and particularly so in glaucomas with alarming 24-h IOP characteristics [33-35]. However, concerns exist if FCs are employed without a clear understanding of the clinical profile and safety of the components [24]. In doing so the efficacy of the individual components may not be confirmed and safety issues are not adequately appreciated.

If future controlled studies show convincingly the improved efficacy, adherence, and tolerability with FCs, like DTFC, compared with unfixed therapies in real-life glaucoma management this class of drugs will receive wider regulatory approval and become the standard of stepwise therapy. More research is mandated to reasonably establish the rationale, indications, and target cohorts of patients for glaucoma FCs just like the approach adhered to with the systemic fixed-dose medications [38]. A clearer understanding of the contribution of components, the ideal dosing of each FC, and the pharmacodynamics and pharmacokinetics of these medications will optimize stepwise glaucoma therapy in the future.

In July 2012, the FDA approved a new formulation of DTFC called preservative-free (PF) DTFC (Cosopt $\left.\mathrm{PF}^{\circledR}\right)$, which was supplied as a unit dose formulation and which became the first PF FC launched in the US market [39]. In September 2013, Merck \& Co sold the US rights to DTFC to Akorn Inc (Lake Forrest, Illinois, USA). Merck \& Co followed this step in May 2014 by divesting most of their ophthalmic business in Europe and Asia (including DTFC) to 
Santen Pharmaceutical Co. Ltd (Japan). Regulatory evidence [39] and subsequent clinical data $[35,40-44]$ suggested that PF DTFC was at least equivalent in efficacy to preserved DTFC and at the same time provided a tangible clinical benefit in patients with glaucoma suffering from ocular surface disease (OSD).

In February 2019, Santen Pharmaceutical was granted a license by the relevant European authorities to launch a novel multidose bottle for PF DTFC in 29 European countries (Cosopt iMulti $\left.{ }^{\circledR}\right)$. The multidose PF DTFC bottle was developed by Nemera and has the theoretical advantage of needing a low squeeze force to instill a drop, thereby improving ease of use for the elderly [45]. Thus, currently PF DTFC is provided by Santen Pharmaceutical in Europe and in several other countries worldwide in both single and multidose formulations. Cumulative evidence indicates that long-term IOP-lowering therapies elicit chronic, low-grade ocular surface inflammation which constitutes an important risk factor for a higher rate of adverse events, reduced tolerability, unsuccessful therapy, enhanced scarring, and subsequent failure of filtration surgery [16, 46, 47]. PF FCs eliminate the toxic effect of preservatives, confer a long-term benefit for patients on lifelong IOP-lowering medical therapy, and may represent the future of lifelong medical therapy $[46,48-50]$. There is, however, still insufficient controlled evidence demonstrating the precise impact of PF medications upon the long-term success of glaucoma therapy $[16,40]$. Moreover, there is still a limited range and availability of PF medications in many countries worldwide.

As highlighted above, PF DTFC represents a promising future option for stepwise therapy. The delivery of PF medications, however, raises methodological issues with industry and regulatory dilemmas. At present, single-dose units are the most popular way to deliver PF medications to the eye. Nevertheless, drawbacks are noted for single-dose pipettes: the higher cost, possible corneal injury, and the challenged handling by elderly patients $[51,52]$. Reduced vision, impaired hand-to-eye coordination, or tremor may hinder the successful administration of PF medications from single-dose units. According to one study, elderly patients with neurotrophic corneal problems may be at particular risk of developing corneal abrasions from uncontrolled contact between the dispenser tip and corneal surface [51]. In contrast, another study did not find a problem with unit-dose pipettes [53] and large controlled trials employing single-dose units for hundreds of patients have not identified or reported corneal injuries [54-56]. Even though the multidose PF DTFC formulation represents a promising development for future stepwise PF therapy more research is needed with comparative studies between the unit-dose and the multidose delivery systems of PF DTFC. Ideally, future studies should also evaluate whether PF DTFC provides a better quality of life compared to preserved DTFC.

In the current review we first present regulatory and postmarketing evidence for the historical preserved DTFC brand, evaluate key aspects of this FC (e.g., 24-h efficacy), highlight the current role of DTFC, and finally outline future directions with the use of the recently launched PF DTFC formulation. This article is based on previously conducted studies and does not contain any studies with human participants or animals performed by any of the authors.

\section{PHARMACOLOGICAL PROPERTIES OF DTFC}

DTFC combines two inhibitors of aqueous humor synthesis: the topical inhibitor of carbonic anhydrase (CA) dorzolamide $2 \%$ together with a non-selective beta-blocker (timolol maleate $0.5 \%)$. Combining two different molecules in the same formulation entails certain compromises concerning the chemical composition of the formulation and its dosing. Dorzolamide merits particular attention for its IOP-lowering effect generated by the inhibition of the carbonic anhydrase enzyme (EC 4.2.1.1) catalyzing the hydration of $\mathrm{CO}_{2}$ to bicarbonate and protons in the ciliary processes $[57,58]$. It is worth noting that the first-generation CA inhibitors (CAIs) were heterocyclic sulfonamides like acetazolamide, methazolamide, and ethoxzolamide and were originally developed for 
systemic administration as diuretics [59]. Their systemic use and the observation that the firstgeneration CAIs had effects on most of the known 15 CA isoforms resulted in a wide range of systemic side effects like fatigue, malaise, weight loss, tingling of extremities, hypokalemia, metallic taste, and gastrointestinal irritation, thereby limiting their clinical usefulness in the chronic therapy of glaucoma. Therefore, the first-generation CAIs are currently employed mainly for the treatment of ocular emergencies, or are prescribed for a short period of time. The significant range of systemic side effects of these medications elicited considerable research interest in the development of topical CAI eye drops that would diminish systemic absorption.

The increasing insight into the role of various CA isoforms in the human body allowed the development of more suitable compounds for ophthalmic use. One of the obstacles for the formulation of topical CAIs was overcome by the use of water-soluble sulfonamides [60], a strategy that finally led to the commercial development of dorzolamide [61]. Dorzolamide is a thiophene and a potent CA-II inhibitor having also an effect on CA-XII and CA-IV. The CA-II is the most important isoenzyme involved in aqueous humor secretion and its inhibition reduced the formation of bicarbonate ions, thereby inhibiting sodium and fluid transport. Importantly, the IOP-lowering effect of dorzolamide is solely dependent on the decrease in aqueous inflow [62]. Subsequent clinical studies demonstrated that the efficacy of topical dorzolamide $2 \%$ solution on human eyes varied between $17 \%$ and $32 \%[63,64]$. In general, the reduction of aqueous flow with dorzolamide has been inferior to that obtained by timolol [64]. Nevertheless, the IOP-lowering effect is additive when the two medications are combined [65]. A noteworthy attribute is that both acetazolamide and dorzolamide are effective and lower aqueous inflow during sleep $[66,67]$.

Timolol maleate has been employed in glaucoma therapy for more than 40 years. Similarly to acetazolamide, timolol was first developed for systemic use and after that was successfully adopted by ophthalmologists for the treatment of glaucoma and ocular hypertension. Since 1977 it has been proven to be an efficacious and safe topical drug for longterm IOP lowering [68]. Timolol is a propanolamine derivative and a non-selective beta receptor blocker without intrinsic sympathetic activity, influencing IOP mainly by reducing aqueous inflow [69]. Despite being used for almost 4 decades in glaucoma management the precise mechanism by which timolol decreases IOP is not completely understood. The reduction of ciliary body blood flow and cAMP production are likely candidates in this process. In clinical studies and in practice the aqueous solution of timolol has been administered twice daily even though slow-release timolol formulations have been shown to be both effective and safe [70-72]. The range of IOP reduction has been demonstrated to be $20-28 \%$ [73-75]. In general, the topical side effects of timolol are relative uncommon and generally mild. However, the systemic adverse effects are relatively common and potentially life-threatening as a result of the effective systemic absorption of timolol via the nasal mucosa [70, 76-79]. The most commonly encountered systemic adverse events of beta blockers are bradycardia and exacerbation of chronic obstructive pulmonary disease [76-79]. Plasma concentration of timolol following topical application varies considerably and is dependent upon pharmacogenetic factors like CYPD2D6 genotypes [80].

Combining two different drugs into a topical formulation is challenging and certain pharmacological issues must be taken into account. In a FC, like DTFC, there are complex interactions between the two active ingredients and the other constituents resulting in clinical advantages and disadvantages versus concomitant therapy with the two constituents. From the pharmacological standpoint the optimal $\mathrm{pH}$ of dorzolamide and timolol maleate in aqueous solution is 5.6 and 7.0, respectively. In the case of DTFC its $\mathrm{pH}$ has been set between 5.6 and 5.8 , which may not be optimal in terms of local tolerability. Furthermore, the duration of dorzolamide action is shorter than that of timolol and thus its optimal dosing is considered to be three times daily. Regulatory [17] and subsequent 24-h IOP studies [33, 81-83] with DTFC dosed twice daily (discussed elsewhere in this 
review) have not shown this to be a problem. This may be due to the intricate pharmacological interaction between the two constituents of DTFC with the IOP-lowering activity and duration of action of timolol dosed twice daily flattening the 24-h IOP curve to such an extent that the b.i.d. dosing of dorzolamide is sufficient.

\section{LEARNING FROM THE PAST: REGULATORY EVIDENCE WITH PRESERVED DTFC}

Two early landmark studies have evaluated the efficacy and safety of DTFC dosed twice daily versus its individual components, each administered in their licensed monotherapy dose (i.e., timolol twice daily, dorzolamide three times daily) $[18,19]$. Two other such studies have compared DTFC versus the concomitant administration of the two constituents, each dosed according to their respective monotherapy regimen (i.e., timolol twice daily, dorzolamide three times daily) [20], or according to the usual clinical practice in adjunctive therapy (i.e., twice daily for both timolol and dorzolamide) [17].

In the 3-month, double-masked, randomized, multicenter study by Boyle et al. [18] with 355 patients with open-angle glaucoma (OAG) or ocular hypertension (OHT), the efficacy and safety of DTFC versus its individual constituents was investigated. To ensure masking, DTFC was dosed twice daily along with placebo once daily, timolol $0.5 \%$ was dosed twice daily along with placebo once daily, whereas dorzolamide $2 \%$ was dosed three times daily. The IOP was measured at morning trough (immediately before instillation) and at morning peak $(2 \mathrm{~h}$ post instillation) on day 1 , week 2 , and months 1,2 , and 3 . After 3 months of treatment, the mean IOP reduction from baseline at morning trough for DTFC, dorzolamide, and timolol was $27.4 \%$, $15.5 \%$, and $22.2 \%$, respectively. At morning peak, the mean IOP reduction from baseline after 3 months of treatment for DTFC, dorzolamide, and timolol was 32.7\%, 19.8\%, and $22.6 \%$, respectively. In all visits, the IOP reduction achieved with DTFC was statistically greater than that achieved with either monotherapy. The investigators [18] noted that there were no significant differences between DTFC and its components in the proportion of participants with any adverse event, drug-related adverse events, and serious adverse events. Nonetheless, a significantly greater proportion of patients withdrew because of adverse events in the DTFC than in the timolol group (7\% vs. $1 \% ; p=0.035)$. The most frequent adverse events were either ocular or local (e.g., dysgeusia). The most common ocular adverse events for the DTFC group were burning/stinging (18\%), blurred vision (4\%), and itching (4\%); those for the dorzolamide group were burning/ stinging (14\%), blurred vision (4\%), and injection (4\%); those for the timolol group were burning/stinging (6\%), blurred vision (4\%), and discharge (4\%). The severity of these symptoms was generally mild, and only one patient from the DTFC arm withdrew as a result of burning/ stinging.

In a similarly designed 3-month, parallel group, double-masked, randomized, multicenter study, Clineschmidt end collaborators [19] investigated the efficacy and safety of DTFC administered twice daily versus each of its constituents administered according to the licensed monotherapy dose, i.e., timolol $0.5 \%$ twice daily and dorzolamide $2 \%$ three times daily. The investigators recruited 253 participants with OAG or OHT who were poorly controlled on timolol monotherapy. At month 3, the mean IOP reductions at trough measurement (i.e., 9:00 A.M., just before the morning timolol instillation) were $10.6 \%(2.8 \mathrm{mmHg})$, $4.9 \%(1.4 \mathrm{mmHg})$, and $6.7 \%(1.7 \mathrm{mmHg})$ for the DTFC, dorzolamide, and timolol groups, respectively. At month 3, the mean IOP reduction from baseline at peak measurement (i.e., 11:00 A.M., $2 \mathrm{~h}$ after the morning timolol instillation) was $17.3 \% \quad(4.4 \mathrm{mmHg}), \quad 7.4 \%$ $(2.0 \mathrm{mmHg})$, and $6.6 \%(1.6 \mathrm{mmHg})$ for the DTFC, dorzolamide, and timolol groups, respectively. The difference in IOP reduction using DTFC was significantly greater than using any of the monotherapies at trough and peak measurements for virtually all time points, including the 3-month visit. Of 253 recruited patients, 232 (92\%) completed the study. Of the 21 patients who withdrew, three did so because 
of drug-related adverse events: two patients in the DTFC group (one with eye pain and one with dizziness, nausea, and tremor) and one in the timolol group (urinary frequency). The most common ocular symptoms for all groups were blurred vision (DTFC: 2\%, dorzolamide: 4\%, timolol: 7\%), burning/stinging (DTFC: 30\%, dorzolamide: $24 \%$, timolol: $8 \%$, and tearing (DTFC: $3 \%$, dorzolamide: $2 \%$, timolol: $2 \%$ ). The most commonly encountered adverse ocular sign was conjunctival hyperemia (DTFC: 9\%, dorzolamide: $12 \%$, timolol: $8 \%$ ). The most frequent non-ocular symptom was dysgeusia (DTFC: $8 \%$, dorzolamide: $7 \%$, timolol: $2 \%$ ).

Another 3-month, double-masked, randomized, multicenter study with an open-label extension for another 9 months evaluated the efficacy and safety of DTFC versus the concomitant administration of timolol $0.5 \%$ dosed twice daily along with dorzolamide $2 \%$ dosed three times daily [20]. In the masked phase, 242 patients with OAG or OHT who were insufficiently controlled on timolol monotherapy were randomized to one of the two arms, whereas in the open-label extension 220 patients received DTFC for another 9 months. IOP measurements were performed just before the morning instillation (hour 0 , at 8:15 A.M.), $2 \mathrm{~h}$ later (hour 2), and $8 \mathrm{~h}$ later (hour 8 ) on days $1,15,30,60$, and 90 of the masked phase. During the open-label extension, the IOP was measured only at hours 0 and 2 on days 180 , 270 , and 365 . Of the 242 enrolled participants, 220 (91\%) completed the masked phase and entered the open-label extension; of these 220 participants, 203 (92\%) completed the extension phase. At 3 months, the IOP reduction at hours 0,2 , and 8 for DTFC was 13.8\%, 19.7\%, and $14.9 \%$, whereas the corresponding IOP reduction for the concomitant group was $15.5 \%, 19.1 \%$, and $17.4 \%$, respectively. At the 3-month time point, the authors estimated that the difference between treatments (IOP of DTFC group - IOP of concomitant group) at hour 0 , hour 2, and hour 8 were - $0.52 \mathrm{mmHg}$, $0.17 \mathrm{mmHg}$, and $-0.69 \mathrm{mmHg}$. According to the authors, the criterion of equivalence (less than $1.5 \mathrm{mmHg}$ difference) was satisfied with greater than $96 \%$ confidence at all time points and all visits during the masked phase. During the open-label phase, the IOP reduction was generally similar to the one observed during the masked phase, thus confirming that the efficacy of DTFC is maintained at least over the 12 months of treatment. Both during the masked and the open-label phase, the most frequent symptoms were bitter taste, blurred vision, and ocular burning. In general, the incidence of most symptoms was very similar in the two groups. The most common ocular signs during the masked period were conjunctival hyperemia and punctate epithelial keratitis, both in comparable prevalence in the two therapy groups (12-14\%). Ocular signs in the open-label period tended to be somewhat less common than in the masked period. Drug-related adverse events occurred in $10 \%$ of participants in each treatment group during the masked period, but only in $6 \%$ of participants during the open-label phase. Ten patients withdrew because of adverse events during the masked phase (DTFC: $n=7$; concomitant therapy group: $n=3$ ) and three patients during the extension phase. Drug-related ocular adverse events, such as eyelid reactions, allergy, and blurred vision, accounted for half of the withdrawals during the masked phase and one-third of the withdrawals during the open-label phase.

Hutzelmann and coworkers [17] conducted a 3-month, double-masked, randomized, multicenter study, and compared the efficacy and safety of DTFC dosed twice daily versus the concomitant administration of timolol $0.5 \%$ dosed twice daily and dorzolamide $2 \%$ dosed twice daily. The study recruited 299 patients with either OAG or OHT who were insufficiently controlled with topical timolol. After a 2-week timolol run-in period, the IOP was measured at trough (8:30 A.M.) and peak (10:30 A.м.) at baseline (day 1$)$ and on days 15 , 30, 60, and 90. Compared to timolol-treated baseline, the mean IOP reduction with DTFC ranged between $3.8 \mathrm{mmHg}$ and $5.8 \mathrm{mmHg}$ (14.6-23.3\%), whereas the IOP reduction with the concomitant administration ranged between $\quad 3.6 \mathrm{mmHg}$ and $5.8 \mathrm{mmHg}$ (14.0-23.2\%). The mean difference (IOP in concomitant group - IOP in DTFC group) in trough and peak measurements averaged over the month 2 and month 3 visits was 
$0.01 \mathrm{mmHg}(95 \%$ CIs -0.52 to 0.55$)$ and $0.08 \mathrm{mmHg}$ (95\% CIs - 0.45 to 0.60$)$, indicating that both study regimens demonstrated virtually identical efficacy. Of the 299 patients who were recruited, 290 (97\%) completed the study. Of the nine who withdrew, three did so because of adverse events (DTFC group: $n=2$, concomitant: $n=1$ ) and the rest because of other reasons. Overall, the same proportion of patients from each group (34\%) experienced at least one treatment-related ocular symptom. These included burning (DTFC: 13\%, concomitant therapy: $9 \%$ ), stinging (9\% in each group), itching (DTFC: 9\%, concomitant therapy: 6\%). The only symptom significantly more common with concomitant therapy was eye pain (DTFC: $0 \%$, concomitant therapy: $4 \% ; p=0.014)$. The most frequently noted ocular sign was conjunctival hyperemia ( $9 \%$ in each group). Importantly, patients in the concomitant therapy group exhibited a significantly greater rate of corneal signs overall ( $14 \%$ vs. $5 \% ; p=0.011)$, and specifically superficial punctate keratitis (7\% vs. $1 \% ; p=0.005$ ).

\section{DTFC THERAPY EMPLOYED IN THE REAL WORLD}

It is widely accepted that the results obtained in the industry-sponsored pivotal clinical trials are not identical to those the clinician observes in clinical practice. Several explanations for this well-known phenomenon have been suggested, but probably the more intuitive one is that reallife patients are less "ideal patients" than those recruited in clinical trials. This may be accounted by the more diverse forms and worse stage of glaucoma these patients may suffer. Moreover, real-life patients exhibit a wide range of comorbidities and their motivation, persistence, and adherence to therapy may be inferior to those participating in trials. In addition, in pivotal trials, the industry usually tailors the study design to obtain just the results needed for approval. For these reasons it is the time after the drug is commercially available when multiple studies in real life are conducted, when the clinician may obtain more comprehensive, clinically relevant, and less biased information about a novel medication.

In this sense, it is important that DTFC has demonstrated similar efficacy in both OAG and OHT to the concomitant administration of the two constituents separately [21]. More surprisingly, it has also been shown in postmarketing trials that when the patients replace concomitant medications with DTFC there is a further improvement in IOP control by up to $1.7 \mathrm{mmHg}$ [21]. This surprising finding may be explained by improved patient adherence and also by the lack of the washout effect with the use of the FC. It is known that when two different eyedrops are administered consecutively without waiting at least $5 \mathrm{~min}$ between them, the second drop partially washes out the first one before complete absorption has occurred, thus leading to suboptimal drug efficacy.

Another aspect not addressed by the pivotal trials was the optimal dosing of DTFC. Shemesh et al. [84] described that on increasing the daily dose from the recommended twice daily to three times daily there was a significant further improvement in IOP lowering with DTFC obtaining an additional $2 \mathrm{mmHg}$ IOP decrease without a concomitant increase in the number of adverse events [84]. In addition to the previously well-documented efficacy in patients with OAG or OHT, DTFC has been reported to obtain a clinically meaningful IOP reduction of more than $20 \%$ in patients suffering from normal tension glaucoma (NTG) with a baseline IOP of $15.6 \mathrm{mmHg}$ [85].

Furthermore, in patients already treated with latanoprost monotherapy and requiring further IOP lowering, the addition of DTFC has been shown to significantly enhance IOP lowering, thus confirming the meaningful adjunctive effect of DTFC when employed with a prostaglandin even in eyes with a treated IOP in the mid-teens [86].

DTFC is not the only topical FC combining a topical CAI with timolol. Brinzolamide, another topical CAI, has been successfully combined with timolol in a FC, the brinzolamide/timolol fixed combination (BTFC, Azarga ${ }^{\circledR}$, Novartis Europharm Ltd, Dublin, Ireland). DTFC and BTFC demonstrate equivalent efficacy [87], but they differ in terms of tolerability. Patients 
report more stinging/burning after the instillation of DTFC, but on the other hand, patients complain more often of blurred vision after the application of BTFC [87]. These differences may be attributed to the lower pH level of DTFC and the fact that BTFC is a suspension and not a solution like DTFC. Both FCs have been found to be equivalent in terms of IOP-lowering effect when added in eyes already on latanoprost monotherapy [88].

Another quite popular $\mathrm{FC}$ is the brimonidine/timolol FC (BmTFC, Combigan ${ }^{\circledR}$, Allergan, Inc., Irvine, CA, USA). Budengeri et al. published a well-conducted meta-analysis of several trials analyzing the safety and efficacy of BmTFC versus DTFC in the treatment of patients with OAG or OHT [89]. Their conclusion was that the safety and daytime efficacy of these two FCs were comparable when employed in patients with OAG or OHT. However, in patients with steroid glaucoma BmTFC may obtain a greater hypotensive effect than DTFC [90]. This finding suggests that the effect on the trabecular meshwork of topically applied adrenergic agents may be beneficial in steroid glaucoma.

DTFC has also been compared with another class of FCs: the prostaglandin/timolol FCs (PTFCs) that combine two drugs with complementary mechanism of action. Most of the comparative evidence is with the latanoprost/timolol FC (LTFC, Xalacom ${ }^{\circledR}$, Pfizer Inc., New York, NY, USA). In most published studies DTFC has been shown to have equivalent hypotensive efficacy compared with LTFC when employed in patients with OAG or OHT insufficiently controlled with monotherapy [91]. This may be surprising since in previous daytime studies DTFC and latanoprost have been reported to demonstrate similar efficacy [92]. Thus, in the case of LTFC it would appear that adding timolol to latanoprost in a FC has a very modest IOP lowering. With regard to the other PTFCs the evidence is limited, but travoprost/timolol FC (DuoTrav ${ }^{\circledR}$, Novartis Europharm Ltd, Dublin, Ireland) seems to provide slightly greater efficacy than DTFC [93] and bimatoprost/timolol FC (Ganfort ${ }^{\circledR}$, Allergan, Irvine, CA, USA) has been reported in one study to be superior to DTFC [94].
There is compelling evidence suggesting that DTFC may be more effective than latanoprost over $24 \mathrm{~h}$ and as initial therapy (both topics are discussed at length below) and in patients undergoing small incision cataract surgery [95]. Further, it should be borne in mind that although the majority of published studies discussed here test the hypotensive efficacy of medications, such as DTFC, in primary open angle glaucoma (POAG) or patients with OHT, there are other clinical scenarios, e.g., secondary glaucomas like exfoliative glaucoma and angleclosure glaucoma, where the efficacy profile and comparative outcome versus other therapy options may be completely different.

\section{OVERVIEW OF THE 24-H EFFICACY OF DTFC}

A single IOP reading provides evidence for only 1 min of the day and does not reflect the dynamic IOP equilibrium during the other 1439 min of that day, or the IOP variation between visits [96-101]. Owing to time/cost considerations current clinical practice involves single sitting IOP readings at each patient visit. Consequently, for most of the 24-h period true IOP levels remain largely unknown. More alarmingly, the quality of IOP data on which we rely to diagnose and treat glaucoma is inadequate and can be misleading [98, 100-103]. This implies that in many patients with glaucoma we simply guess what the real 24-h IOP control may be. Even in certain academic centers where 24-h IOP monitoring is routinely performed we only monitor 4-6 IOP readings in selected patients. This approach does not resemble systemic blood pressure monitoring and the IOP evidence thus obtained will only reveal a partial picture of true IOP pathology in a given patient with glaucoma [104-107].

In glaucoma management, pharmacological and surgical therapy options are employed to substantially lower IOP, the only modifiable risk factor for the development and progression of glaucoma [108]. IOP, however, is not fixed but varies considerably during the 24 -h period $[98,101,106,107]$. Since glaucoma is a $24-\mathrm{h}$ disease, follow-up in clinical practice with 
single IOP readings remains a major limiting factor in glaucoma care, resulting in lack of robust IOP evidence collection over time $[97,101,104,105,109,110]$. Only by evaluating 24-h IOP characteristics (mean, peak, and fluctuation) at diagnosis and after therapeutic interventions can we appreciate the true efficacy of therapy [101, 109, 111]. While 24-h IOP monitoring is a relatively new arrival in the research of glaucoma, convincing evidence indicates that there are substantial increases in IOP occurring during the 24 -h period that negatively impact glaucoma progression [98, 101, 108]. These IOP peaks, large 24-h fluctuation, and substantial long-term IOP variation often elude detection and thus are not sufficiently treated. Furthermore, recent research has highlighted the importance of targeting nocturnal IOP control to halt glaucomatous disease progression [108]. There remains, therefore, a need for selecting glaucoma medications that can effectively control IOP day and night and for novel IOP-lowering therapies capable of managing 24-h IOP characteristics comprehensively to mitigate disease progression.

Consequently, to determine the true efficacy of DTFC it is necessary to document its 24-h IOP characteristics and to compare the efficacy of this FC with other available treatment options over $24 \mathrm{~h}$. DTFC is currently the IOP-lowering FC with the most comprehensive published 24-h evidence detailing its 24-h efficacy and 24-h IOP characteristics $[23,33,40,81-$ $83,112-116]$. With regard to the 24-h efficacy of DTFC, most research has demonstrated that the timolol constituent, as a $\beta$-blocker, induces a greater IOP reduction during the day and a less, albeit still significant, IOP reduction during the night [117-119]. Timolol lowers IOP by reducing aqueous humor flow, but has no effect on outflow resistance or on episcleral venous pressure [120]. It is reasonable to hypothesize that the decreased activity of timolol during the night is due to either the inability of betaadrenergic antagonists to reduce further nocturnal aqueous humor flow or to increased pressure in the episcleral venous system in the supine position [121, 122]. Aqueous humor flow is reduced by approximately $45 \%$ during sleep, in comparison to flow during waking hours $[119,122]$, and this may explain the reduced activity of timolol [119].

In contrast, it is well established that dorzolamide significantly reduces aqueous synthesis at night $[99,123]$. Indeed, a meta-analysis of 24-h studies demonstrated that dorzolamide was the only IOP-lowering monotherapy working better during the night than during the day [111]. Accordingly, dorzolamide reduced IOP by 20-23\% between 22:00 and 06:00 and only by 14-18\% between 10:00 and 18:00 during the day. Thus, dorzolamide consistently lowered IOP more than timolol and to the same extent as latanoprost during nighttime $[81,111]$. This was also consistent with the nighttime decrease in aqueous humor flow obtained by dorzolamide in the study by Vanlandingham and coworkers [67].

The 24-h characteristics of DTFC have been evaluated in several controlled studies $[23,33,40,81-83,112-116]$. In the majority of these studies the 24-h efficacy of DTFC was compared with that of other ocular hypotensive drugs, or regimens, in subjects with OAG or OHT. The overall mean 24-h IOP reduction reported ranged between $25 \%$ and $33 \%$ and DTFC provided consistent 24-h IOP reduction with relatively narrow fluctuation of 24 -h IOP (3.8-4.6 mmHg), which improved slightly over time $[83,104]$.

The first controlled study to document the efficacy of DTFC over the complete 24-h period was carried out by Konstas and coworkers in 2003 [82]. These authors reported that DTFC provided significantly better 24 -h IOP control $(-0.6 \mathrm{mmHg})$ than latanoprost mainly owing to the greater efficacy of DTFC at night (22:00 time point). This was a single-masked, crossover comparison in 34 patients affected by POAG or OHT. After 6 weeks of therapy the mean 24-h IOP was statistically lower with DTFC $(15.3 \pm 2.0 \mathrm{~mm})$ versus that with latanoprost $(15.9 \pm 2.3 \mathrm{mmHg}) \quad(p=0.05) \quad[82]$. The trial highlighted the importance of conducting a complete 24-h IOP assessment when evaluating two IOP-lowering medications. While daytime pressures were equal between DTFC and latanoprost in the evening (22:00) there was an 
efficacy advantage of the FC compared to latanoprost [82].

In another crossover 24-h study Orzalesi and associates [112] compared latanoprost, brimonidine tartrate, and DTFC over $24 \mathrm{~h}$ in patients with POAG or OHT. All the drugs significantly reduced IOP compared with the baseline at all times, except for brimonidine at midnight. The authors observed similar IOP control between latanoprost and DTFC except at 09:00 when DTFC was significantly more effective.

In a larger, longer-term, randomized, prospective, crossover 24-h IOP study on 53 patients with POAG or OHT, Konstas and associates [83] compared the 24-h IOP efficacy of the DTFC versus latanoprost over 2 and 6 months. After 2 months of therapy, DTFC provided significantly better IOP control than latanoprost at three time points (10:00, 18:00, and 22:00) and for the mean $24-\mathrm{h}$ IOP $(18.0 \pm 1.8$ vs. $18.6 \pm 1.9 \mathrm{mmHg} ; \quad p=0.0002)$. Following 6 months of chronic treatment both medications reduced mean untreated 24-h IOP (25.2 $\mathrm{mmHg}$ ) to a similar extent: $18.1 \mathrm{mmHg}$ with DTFC and $18.3 \mathrm{mmHg}$ with latanoprost. DTFC still provided significantly better IOP at two time points (10:00 and 22:00; $p<0.01$ ) [83]. Feldman and coworkers [115] carried out an 8-week randomized, parallel, doublemasked, multicenter study evaluating the 24-h efficacy of DTFC in patients with OAG and OHT insufficiently controlled on timolol. They reported that DTFC significantly reduced IOP throughout the 24-h period when compared to timolol treated baseline. Compared with timolol alone, there were significantly greater reductions with DTFC at 10:00 $(p=0.003)$ and $14: 00(p=0.016)$, and for the mean daytime IOP $(p=0.025)$.

Further evidence of greater 24-h IOP lowering with DTFC in comparison with latanoprost has been provided by Quaranta and coworkers [114]. In a crossover 24-h study on patients with previously untreated POAG, they observed a significant difference in 24-h efficacy in favor of the DTFC $(-1.3 \mathrm{mmHg} ; p<0.0001)$ when compared to latanoprost monotherapy. The greater 24-h separation between DTFC and latanoprost observed between this and the other two previously conducted comparative studies may be attributable to the fact that DTFC was employed as initial therapy in the Quaranta study [114] and thus this study avoided the inclusion of timolol non-responders.

Another 24-h study compared DTFC to the latanoprost/timolol FC (LTFC) in 32 patients with glaucoma insufficiently controlled on latanoprost monotherapy. In this DTFC reduced mean 24 -h IOP by $2.2 \mathrm{mmHg}$ (10\%) more than latanoprost baseline and to a similar extent to LTFC dosed in the evening $(-2.6 \mathrm{mmHg}$, $11.8 \%)(p=0.59)$ [113]. Of note in this study the largest additional $24-\mathrm{h}$ IOP reduction was obtained when DTFC dosed twice daily was combined with latanoprost dosed in the evening $(-5.6 \mathrm{mmHg},-25.4 \%)$.

In a double-masked, two-center, crossover comparison Konstas and coworkers [124] investigated the mean diurnal IOP control with either DTFC dosed twice daily or the LTFC dosed once in the morning. These authors monitored IOP every $2 \mathrm{~h}$ over a period of $12 \mathrm{~h}$ in 33 patients with either glaucoma or OHT. The mean diurnal IOP for DTFC $(17.0 \pm 2.0 \mathrm{mmHg})$ was similar to that recorded with LTFC $(17.2 \pm 2.2 \mathrm{mmHg}) \quad(p=0.36)$. Moreover, no difference was obtained between the two FCs for any of the six time points measured. In contrast, Eren and coworkers [116] conducted a double-masked, 6-week, crossover 24-h study comparison between DTFC and LTFC dosed in the evening in patients with POAG and reported the mean 24-h IOP to be statistically lower with the LTFC $(16.3 \mathrm{mmHg})$ than with the DTFC (17.3 $\mathrm{mmHg})$. The reason for the difference between these clinical studies may be the shorter duration of the second study and the different dosing of LTFC (morning vs. evening).

In a large, multicenter trial Konstas and coworkers [23] compared DTFC and the brimonidine/timolol FC over $24 \mathrm{~h}$. One eye each of 77 patients with POAG was included in this prospective, observer-masked, crossover, 3-month comparison. Following a 2-month timolol run-in period 60 timolol responders were included in this trial. When the two FCs were compared directly, DTFC demonstrated a lower mean 24-h IOP level as compared with the brimonidine/timolol FC (mean difference - 
$0.7 \mathrm{mmHg}, 95 \%$ confidence interval - 1.0, $0.3 ; p<0.0001)$. At two individual time points (18:00, 02:00) DTFC reduced IOP significantly more than brimonidine/timolol FC $(p=0.001)$. The largest difference between the two FCs was observed at 18:00 $(-1.1 \mathrm{mmHg})$ [23]. The results of this trial were consistent with previous 24-h investigations showing reduced or almost no efficacy of brimonidine at night $[119,125,126]$.

To conclude, there is today convincing evidence supporting the view that DTFC is an effective day and night medication providing relatively uniform IOP lowering over the complete 24-h period. Available controlled 24-h evidence suggests that the timolol component works more effectively during the day and the dorzolamide component works better during the night. However, the picture is not entirely clear concerning the 24-h efficacy of DTFC compared other FCs especially the newer FCs. The 24-h efficacy of PF DTFC versus other PF glaucoma medications as well its role in stepwise glaucoma therapy of the future requires further elucidation.

\section{ASSESSING THE IMPACT OF DTFC ON OCULAR BLOOD FLOW AND POSSIBLE THERAPEUTIC IMPLICATIONS}

For decades, systemic carbonic anhydrase inhibitors have been known to be potent vasodilators in the brain [127-129] and studies have shown that systemic acetazolamide also increases perfusion at the posterior pole of the eye [130-132]. As such, there is interest in whether ocular vasodilator effects can also be achieved with topical formulations of carbonic anhydrase inhibitors. However, investigation of such vasodilator effects is not straightforward as antiglaucoma drugs increase ocular perfusion pressure (OPP) by reducing IOP and an increase in blood flow can therefore either be caused by the increase in OPP or by a direct pharmacological effect at the posterior pole of the eye [133]. Hence, the question is whether dorzolamide and/or brinzolamide would reach the posterior pole of the eye in a concentration that is sufficient to elicit vasodilator effects. Animal studies have shown that topical carbonic anhydrase inhibitors can be detected in the retina [134-136], but to what degree such data can be translated to human eyes with their much larger volume remains to be proven.

In vitro studies have documented dose-dependent vasodilator effects of dorzolamide [137-140] and brinzolamide [139]. The majority of clinical studies have used dorzolamide or brinzolamide alone to investigate whether changes in blood flow can be observed. A wide variety of methods were used for assessing perfusion-related parameters after dorzolamide including pulsatile ocular blood flow and pulse amplitude [141], laser Doppler flowmetry [142-144], laser Doppler velocimetry [145], laser-interferometric measurement of fundus pulsation [142], quantitative fluorescein angiography [146-149], and color Doppler imaging [146-148, 150-154], and increase in ocular blood flow parameters was indicated in the majority of the studies after dorzolamide administration. Most studies did, however, suffer from small sample size and non-randomized study design. One 6-week double-masked parallel group trial compared dorzolamide versus placebo in 47 patients with OAG [155]. Ocular perfusion was quantified using color Doppler imaging of the retrobulbar vessels and scanning laser ophthalmoscope fluorescein angiography, but no significant difference was found between the treatment arms.

In the largest study, 140 patients with POAG or OHT were included in a controlled, randomized, double-blind study in two parallel groups comparing topical timolol and dorzolamide for 6 months. Scanning laser Doppler flowmetry was employed to measure blood flow in the temporal neuroretinal rim and the cup of the optic nerve head and pulsatile choroidal blood flow was assessed using laser-interferometric measurement of fundus pulsation amplitude. Whereas the IOP was reduced to a similar degree in both groups, dorzolamide, but not timolol, increased the ocular hemodynamic parameters [142]. In addition, both drugs improved the abnormal pressure/flow relationship [156, 157]. 
There are fewer studies with brinzolamide being published. Klemm and coworkers in 2003 did not observe an effect of a 3- to 5-week therapy on retrobulbar flow velocities or pulsatile ocular blood flow [158], which is in keeping with another study from the same group [154]. One study did, however, report an increase in retinal blood flow as measured with scanning laser Doppler flowmetry in patients with POAG after brinzolamide treatment [144].

The effects of combination therapy with carbonic anhydrase inhibitors and beta-receptor antagonists is less well studied. In an early study, 15 patients with POAG were treated with DTFC and results showed an increased arteriovenous passage time of fluorescein dye indicative of increased retinal blood flow [159]. A subsequent study included 30 subjects with POAG and demonstrated that DTFC, but not latanoprost, increased pulse volume [160]. This is compatible with other studies showing that DTFC increases the end-diastolic velocity in the central retinal artery [161, 162]. Whereas one study used timolol/pilocarpine FC as a comparison in a randomized, crossover study design [161], another study used timolol plus latanoprost as a comparison in a randomized, crossover, double-blind study design [162]. These two studies included 16 patients with POAG each. A subsequent prospective, observermasked, randomized, crossover study used LTFC as a comparator also observed that only DTFC improved retrobulbar flow velocities, as measured with color Doppler imaging [163]. The same group reported that the difference between LTFC and DTFC can still be seen after 1 year of treatment [164].

A general problem with studies investigating the ocular hemodynamic effects of antiglaucoma drugs is the lack of gold-standard technology for measuring blood flow [165-169]. So far, no studies have been published on the effects of carbonic anhydrase inhibitors on OCT angiography parameters. One does, however, need to keep in mind that OCT angiography is currently unable to provide quantitative measurements of perfusion [170-173]. Doppler OCT is a relatively well-validated technique for measuring retinal blood flow [174-179], but commercial instruments are still at the prototype stage [180, 181], and no studies on carbonic anhydrase inhibitors are currently available.

Moreover, it is not established whether an increase in blood flow to the posterior pole of the eye would lead to a reduction in visual field progression independently of IOP-lowering effects [182]. A prospective study was conducted on 161 patients with POAG who were randomized to receive either dorzolamide or brinzolamide added to timolol in a 5-year evaluatormasked study. According to this study the risk for progression in patients treated with dorzolamide plus timolol was approximately half of that in patients treated with brinzolamide plus timolol. Furthermore, an increase in retrobulbar blood velocities was only seen with dorzolamide plus timolol [183] and lower blood velocities were risk factors for visual field progression [182]. However, there is no other study confirming this result. While the majority of published studies indicate that dorzolamide and DTFC increase perfusion at the posterior pole of the eye, the question on how this translates into visual field protection is still unclear. Given the preliminary evidence available it may, however, be justified to initiate a well-designed, multicenter clinical trial to answer this important question.

\section{ASSESSING THE THERAPEUTIC UTILITY OF DTFC EMPLOYED AS FIRST-CHOICE THERAPY IN GLAUCOMA}

Evidence supports the efficacy, safety, and tolerability of DTFC as a potential first-choice therapy in glaucoma management. This FC treatment also has features that may improve long-term adherence to glaucoma therapy, particularly with the added benefits of the recently available PF DTFC formulation. Table 1 lists the several features required of an ideal first-line medication that align with both published evidence [17-20, 22, 29, 71, 92, 112, 184] and clinical experience with DTFC.

Consistent with well-entrenched traditional glaucoma management paradigms, most of the 
Table 1 Features of an ideal first-line drug in glaucoma

\begin{tabular}{ll}
\hline Feature & Fixed combination dorzolamide/timolol \\
\hline Efficacy & Yes \\
Safety & Yes \\
Once daily dosing & No \\
Minimal peak/trough IOP control & Yes \\
Flexibility of dosing time of day & No \\
Preservative-free available & Yes \\
Cost-effective & Yes \\
Brand versus generic & Yes \\
Long-term published evidence & Yes \\
Can be used in patients with allergy to sulfonamides & Yes \\
\hline
\end{tabular}
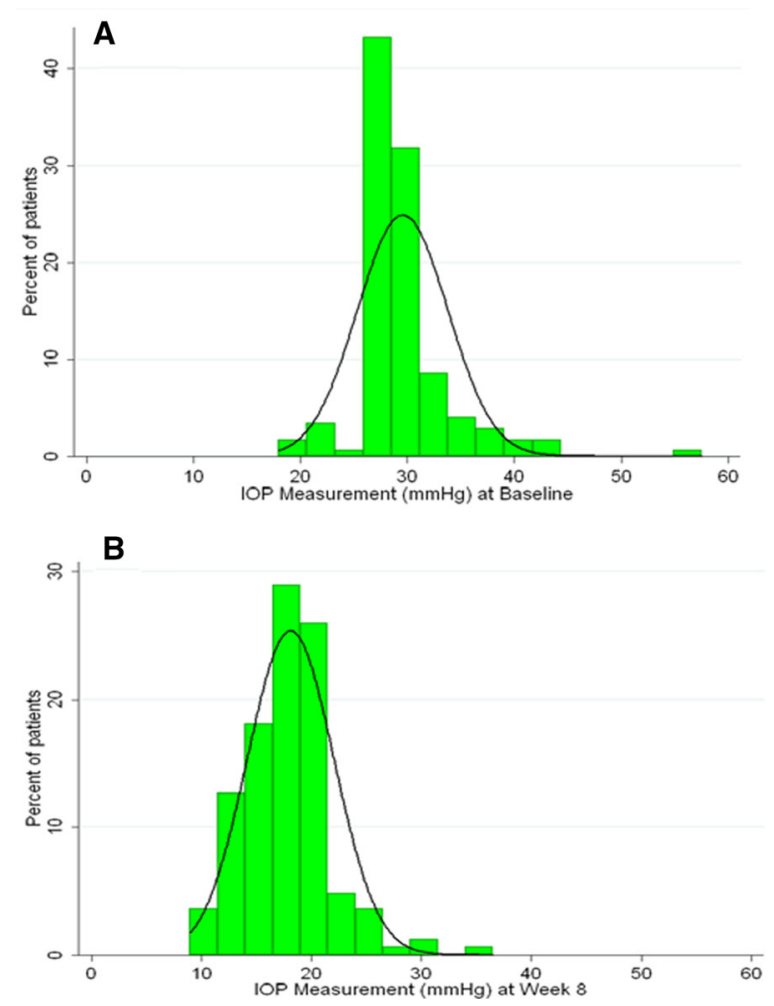

Fig. 1 Distribution of IOP values at baseline (treatment naïve) (a) and after 8 weeks of treatment with PF DTFC (b) published trials compare FC medications to their unfixed components relegating the role of the second agent as adjunctive. Relatively fewer trials have examined the role of FCs as primary therapy in treatment-naïve eyes. Two studies found DTFC very effective as initial therapy $[33,34]$ in patients presenting with high baseline IOP. Within $2 \mathrm{~h}$ of a single dose IOPs fell by up to $48 \%$ with a sustained effect noted 2 months later [34].

Encouraged by the demonstrated efficacy of DTFC, concern about the increasing negative effect of preservatives on the ocular surface $[185,186]$ and the availability of a PF formulation of DTFC in the Canadian market, we conducted a multicenter prospective clinical trial in patients with newly diagnosed and untreated OAG or OHT [35]. The primary endpoint was change in ocular surface signs/symptoms with efficacy being secondary. In total 170 patients completed the 8-week study. The distribution of IOPs pre and post treatment is shown in Fig. 1. The average IOP reduction with PF DTFC was 38\% from baseline. The GSS-SYMP6 assessment tool revealed that treatment-naïve patients had mild to moderate OSD at the time of diagnosis and that PF DTFC was well tolerated with no significant change in ocular surface status after 8 weeks of use. This study found that most treatment-naïve patients present with mild to 
moderate OSD at the time of diagnosis, which is a consideration when choosing an initial therapy. In this trial PF DTFC was found to be safe and well tolerated. It had excellent efficacy that did not seem to be affected by the absence of preservative and it did not seem to exacerbate ocular surface signs/symptoms.

There is a growing body of evidence supporting the use of FC medications earlier in disease management. Globally, and specific to glaucoma management, the healthcare landscape is evolving. Enhanced diagnostic testing has shown that structural glaucomatous damage occurs significantly earlier in the disease than historically recognized [187]. Treatment algorithms are evolving to recommend lower target IOPs earlier in the disease [188]. Collectively the evidence suggests that FCs, which possess many features of an ideal first-line drug, should be a consideration at the earliest stage of the treatment algorithm. This is particularly important in patients with glaucoma presenting with high IOP or other unfavorable 24-h IOP characteristics (e.g., high peak IOP or wide fluctuation of 24-h IOP) such as exfoliative glaucoma or angle-closure glaucoma [33-35].

\section{EMPLOYING DTFC IN CURRENT GLAUCOMA MANAGEMENT}

When DTFC was commercially launched regulatory approval indicated that this FC should be selected for further IOP lowering in patients with OAG or OHT for whom monotherapy with $\beta$-blockers failed to achieve satisfactory IOP control [189]. Since then DTFC has been widely employed in those patients who were responsive to $\beta$-blockers, but whose target pressure could not be reached with $\beta$-blockers alone. Evidently, in such patients stepping up therapy with DTFC offers the advantages of improved efficacy, convenience, same number of eyedrops, same exposure of ocular tissues to preservatives, and possibly decreased cost $[10,15,48]$. This indication has remained a valuable option in certain cases today.

In current glaucoma management, however, prostaglandin analogues have succeeded $\beta$ blockers as first-line therapy $[7,190]$.
Consequently, clinicians may now face the need to either modify a prostaglandin monotherapy because of intolerance/adverse effects or more often require adjunctive therapy when prostaglandins are effective, but the desired target pressure is not reached with prostaglandin monotherapies. It is acknowledged that knowing which class is best suited as second-line therapy remains controversial. Nevertheless, switching from prostaglandin monotherapies to DTFC is a well-established and popular clinical option, although DTFC has not received formal regulatory approval for its use in patients insufficiently controlled on prostaglandin monotherapies. Clearly, more evidence is needed concerning the optimal transition to second-line therapies in patients with glaucoma treated with prostaglandin analogues. There is, however, some convincing evidence that switching from latanoprost monotherapy to DTFC may provide meaningful further IOP reduction with a favorable tolerability profile [113].

Another popular clinical scenario involves the selection of DTFC as adjunctive therapy in prostaglandin-treated patients who require substantial additional IOP lowering (3-$6 \mathrm{mmHg}$ ) to arrest further progression or ultimately loss of vision. These patients tolerate their prostaglandin monotherapy well, but are considered at-risk due to the stage, form, or other considerations pertaining to their therapies and may require more aggressive IOP lowering. In Europe the selection of DTFC as adjunctive therapy to a prostaglandin has evolved to become the most popular indication. Controlled long-term evidence describing the potential clinical benefits and shortcomings of such an approach remains as yet limited $[40,113]$. There are two short-term, controlled 24-h studies that have investigated the adjunctive efficacy of DTFC when added to a prostaglandin. The first study was a prospective, observer-masked, placebo-controlled, crossover comparison [113] in 31 consecutive subjects with OAG who exhibited a mean baseline IOP greater than $21 \mathrm{mmHg}$ on latanoprost monotherapy and were randomized for 3 months to DTFC, LTFC given in the evening, or DTFC and latanoprost. The trial 
demonstrated that a clinically meaningful further 24-h IOP reduction over latanoprost alone may be achieved by switching to either DTFC alone $(-2.2 \mathrm{mmHg})$ or by adding DTFC to latanoprost $(-5.6 \mathrm{mmHg})$. On average, over twice the extent of 24-h IOP decrease was achieved by combining DTFC and latanoprost therapy compared to either DTFC or LTFC given alone. Consequently, on the basis of the extent of IOP reduction demonstrated in this study, a clinician should be able to better judge the second-line therapy that should best achieve an individual patient's pressure goal, by either replacing prostaglandins with a FC or by adding DTFC to a prostaglandin. In a more recent prospective 24-h study, the addition of PF DTFC to PF tafluprost monotherapy achieved a clinically meaningful further IOP reduction at all time points and for the complete 24 -h period (PF DTFC plus PF tafluprost $17.3 \mathrm{mmHg}$ vs. $21.9 \mathrm{mmHg}$ with PF tafluprost alone; $p<0.001$, $21.1 \%$ IOP reduction) [40]. Finally, it is increasingly recognized that a FC may have a role as first-line treatments in certain at-risk patients with glaucoma [33-35, 41, 191].

Overall, the optimal indications and value of DTFC in current glaucoma management remain to be elucidated. Regulatory approval worldwide and the majority of published literature are based on efficacy and safety comparisons between DTFC and the individual components or the concomitant use of both constituents [10]. This approach, however, is not ideal since it does not take into account other possible benefits for the patient such as enhanced adherence, improved convenience, reduced exposure to preservatives, and reduced cost of daily therapy. Inadequate adherence remains today the biggest obstacle in delivering successful therapy by greatly diminishing drug efficacy in real life. Insufficient adherence and persistence lead to under-treatment and disease progression. Ideally, we need to see long-term head-to-head studies comparing DTFC and prostaglandin monotherapies and long-term controlled evidence on the efficacy of DTFC when employed as adjunctive therapy to prostaglandins. A key challenge in optimizing stepwise glaucoma therapy is to keep it practicable. This concept should probably evolve to treatment with no more than three drugs in two bottles, one of which will often be DTFC.

To date the superior efficacy, tolerability, convenience, and decreased medication washout with preserved DTFC compared to the concomitant administration of its constituents are well documented [10]. In the future however, as DTFC is now available in PF multidose and unit-dose formulations in many parts of the world, its selection may offer the added benefit of eliminating ocular tissue toxicity [48]. In view of the recognized problems associated with preservatives, it is becoming difficult to find convincing justification for advocating the use of preserved DTFC as opposed to PF DTFC. The possibility exists that this relatively new formulation may prove instrumental in improving the long-term prognosis of medical therapy in glaucoma.

\section{LOOKING TOWARDS THE FUTURE: PF DTFC}

Topical glaucoma medications are associated with a significant incidence of glaucoma therapy-related OSD. The prevalence of progressive OSD in patients with glaucoma on conventional topical IOP-lowering treatment is particularly high and impedes lifelong glaucoma therapy $[16,186,192]$. Therefore the problem of glaucoma therapy-related OSD has gained increasing importance in glaucoma management in recent decades [16]. In topically treated eyes OSD can be caused by the toxic effects of the active ingredients, but in the majority of the cases it is due to the cumulative toxic effect of benzalkonium chloride (BAK), the most widely used preservative in ophthalmic medications. BAK is a detergent which remains in the tear film for several days after a single instillation and causes tear film instability, hyperosmolarity, Meibomian gland disease, apoptosis, inflammation, and inflammation related alterations in the lacrimal gland function [16, 193-195]. In most cases of glaucoma IOP control requires use of topical IOP-lowering medications for decades. For that reason, complete removal of preservatives from the chronically used glaucoma medications has gained 
particular importance and resulted in the production of various PF topical monotherapies and PF FCs [16]. The PF DTFC was the first PF FC formulation launched in 2012 and manufactured in unit-dose pipettes. Since then it has been increasingly used in routine glaucoma care.

To achieve similar IOP-lowering efficacy the same ocular penetration is required from the $\mathrm{PF}$ formulation as that with the corresponding preserved with BAK formulation. It is known that BAK enhances the penetration of active IOP-lowering molecules via the corneal epithelium by loosening the contact between epithelial cells, due to its toxic effect $[48,196]$. More recently, however, this effect has been shown to be unnecessary for optimal ocular drug penetration for all currently employed IOP-lowering drug classes [16]. In addition, increased corneal penetration can result in the damaging penetration of toxic compounds, including BAK $[46,197]$. In an in vitro experiment conducted on human trabecular meshwork cells cultured in a medium containing tenfold diluted preserved and PF timolol $0.5 \%$ and dorzolamide $1 \%$, respectively, cell viability was $48.5 \%$ with preserved vs. $80.9 \%$ with PF timolol, and $47.0 \%$ with preserved vs. $71.7 \%$ with PF dorzolamide [198]. In another investigation $0.1 \mathrm{ml}$ of preserved DTFC and $0.1 \mathrm{ml}$ of PF DTFC prepared in $1: 1$ dilution ratio was injected in the anterior chamber of rabbits [199]. After $24 \mathrm{~h}$ in the eyes treated with the preserved solution significant corneal edema and endothelial cell loss were recorded, while only mild changes were seen in the eyes injected with the PF drug solution.

The IOP-lowering effect of preserved versus PF DTFC was compared in a 3-month, randomized, double-masked, parallel arm study with a 3-week timolol monotherapy run-in period in 261 patients with glaucoma [39]. The mean baseline IOP on timolol medication was $23.7 \mathrm{mmHg}$ in both arms. Neither statistically nor clinically significant IOP difference was found between the treated groups at weeks 2,6 , and 12 , and the between-group mean IOP differences did not exceed $0.5 \mathrm{mmHg}$ in any visit.

The clinical experience with PF DTFC was reported in two prospective, open-label studies $[35,41]$. In an 8-week investigation of 178 treatment-naïve patients with OAG or OHT, the mean IOP at baseline $(29.6 \mathrm{mmHg}$ ) decreased to $18.1 \mathrm{mmHg}$ (38\% reduction) in the week 8 visit [35]. In the other investigation carried out on patients with glaucoma registered in the German Glaucoma Register (20,506 patients) the mean baseline IOP with or without topical medication $(20.8 \mathrm{mmHg})$ decreased to $16.7 \mathrm{mmHg}$ (17.3\% reduction) after 12 weeks of treatment with PF DTFC [41]. The mean IOP decrease seen on treatment-naïve eyes was $7.9 \mathrm{mmHg}$. Tolerability of the PF DTFC has been reported to be favorable. The Glaucoma Symptom Scale (GSS-SYMP-6) mean total score of treatment-naïve patients with OAG or OHT at baseline (73.6) and at 8 weeks of PF DTFC treatment (76.1) did not differ $(p=0.097)$ [35]. In a similar prospective multicenter 8-week study conducted on 102 patients, in which preserved topical medication was switched for PF DTFC, the mean GSS scale values (total score, symptom score, and function score) all improved significantly $(p<0.0001)$ [42]. In the head-to-head comparison of the preserved and PF DTFC fewer drug-related adverse events (20.6\% vs. $26.9 \%)$ and fewer punctate corneal epithelial erosions were documented in the PF DTFC arm (16.8\% vs. 23.8\%) [39].

In a recent 24 -h investigation it has been shown that the IOP-lowering effect of PF DTFC administered twice daily is additive to that of PF tafluprost administered once in the evening [40]. Finally, PF DTFC has been successfully tried for controlling IOP for 3 months temporizing before planned glaucoma filtration surgery, an intervention for which the preservative related ocular irritation may have a negative effect on surgical success [43].

In 2018 and 2019, two PF multidose DTFC formulations became available in Europe. Both formulations work using the same working principle of unidirectional flow regulation, Novelia $^{\circledR}$ (Nemera, La Verpillière-France), which prevents contamination of the solution stored in the droptainer [45]. In the Novelia ${ }^{\circledR}$ bottle system the sterile solution flows through a one-way valve preventing any contamination ingress. The system also allows drop size control and differences in the stiffness of the droptainer's wall, which has a considerable influence 
on the pressure necessary for successful instillation. In the PF formulation manufactured by Santen Inc. the rigidity of the droptainer's wall is relatively low, while it is relatively high in the other product manufactured by Bausch Health Inc. This difference may help patients find their better individual option. In the Santen product the tip of the droptainer is blue. This can help the patients focusing on the droptainer during instillation point, which may support the instillation precision [200]. It should be borne in mind that to date no head-to-head comparison has been published for the two different Novelia ${ }^{\circledR}$-based multidose PF DTFC formulations. In a recent investigation the PF formulation manufactured by Santen Inc. was compared to $3 \mathrm{~K}^{\circledR}$-System pump (Ursatec, Tholey, Germany), which is a "non-airless" multidose PF system [201], for DTFC instillation. Twenty-nine of the 30 patients preferred the Novelia ${ }^{\circledR}$ bottle since it was significantly easier to open, squeeze, and target, and the removal of the residual drop and the general usability were also better ranked $(p<0.001$ for all comparisons).

A generic PF multidose DTFC system recently launched by Laboratories Théa has been evaluated in an international, multicenter, retrospective, non-interventional, real-life study [44]. Of the 788 patients with OAG and OHT who used the multidose PF system for at least 4 weeks, $78.3 \%$ were satisfied or very satisfied with the droptainer. These results suggest that the PF multidose DTFC formulations are generally well accepted and easy to use.

\section{CONCLUDING REMARKS}

FCs are a popular class of medications in glaucoma therapy principally owing to the success of DTFC, which became the first FDA-approved IOP-lowering FC in 1998. Even after 22 years DTFC remains one of the most prescribed IOPlowering medications worldwide. This review highlights the key clinical attributes of DTFC that align with both published evidence and clinical experience. In regulatory clinical trials DTFC lowers IOP by approximately $9 \mathrm{mmHg}$ $(32.7 \%)$ at peak and by $7.7 \mathrm{mmHg}(27 \%)$ at trough. There is convincing controlled evidence supporting clinical equivalence of DTFC to unfixed concomitant therapy. In real-life practice, however, DTFC and other glaucoma FCs attain better IOP control compared with unfixed concomitant therapies, owing to enhanced convenience, elimination of the washout effect from the second drop, and improved tolerability/adherence. Cumulative data suggest that preserved DTFC, and particularly PF DTFC, may improve tolerability and adherence to lifelong glaucoma therapy.

Switching from prostaglandin monotherapies to DTFC is a well-established and popular clinical option, although DTFC has not received formal regulatory approval for this indication. Another popular clinical scenario is employing DTFC as adjunctive therapy in prostaglandintreated patients who require substantial additional IOP lowering to halt further progression. In the future, more evidence is required concerning the transition to DTFC in patients treated with prostaglandin monotherapies.

There is convincing 24-h evidence supporting the view that DTFC is an effective day and night medication with a relatively uniform IOPlowering effect over $24 \mathrm{~h}$. Several published studies have demonstrated that DTFC increases perfusion at the posterior pole of the eye. However, it remains uncertain whether this finding translates into visual field preservation. DTFC is particularly effective as initial therapy in patients with glaucoma presenting with high baseline IOP. Within $2 \mathrm{~h}$ of a single dose IOP fell by up to $48 \%$ with a sustained effect noted 2 months later. Emerging evidence suggests that DTFC possesses features of an ideal first-line therapy and may be a consideration at the earliest stage of the glaucoma treatment algorithm.

In 2012, PF DTFC became the first PF FC launched on the market, first in unit-dose pipettes, and more recently in a multidose format. Regulatory evidence and subsequent clinical data have confirmed that PF DTFC is at least equivalent in efficacy to preserved DTFC and provides tangible clinical benefits to patients with glaucoma suffering from OSD. Specifically, PF DTFC eliminates the toxic effect of preservatives, enhances long-term tolerability, adherence, and quality of life. Conceivably it may 
confer a long-term benefit for patients with glaucoma who will eventually require filtering surgery. Thus, this new PF formulation may optimize lifelong medical therapy in the future. However, as of yet, there is insufficient controlled evidence evaluating the impact and value of $P F$ medications.

\section{ACKNOWLEDGEMENTS}

Funding. No funding or sponsorship was received for this study or the publication of this article.

Authorship. All named authors meet the International Committee of Medical Journal Editors (ICMJE) criteria for authorship for this article, take responsibility for the integrity of the work as a whole, and have given their approval for this version to be published.

Disclosures. Anastasios G. Konstas: Editorial board member for Advances in Therapy; research funding from Allergan, Bayer Omni Vision, Pharmaten and Santen; travel support and congress expenses from Vianex; honoraria from Allergan, Esteve Pharmaceuticals, Mundipharma, Santen and Vianex. Andreas Katsanos: Advisory board member for Advances in Therapy; honoraria and congress expenses from Cooper SA, Santen, Vianex, Zwitter; research funding from Laboratoires Théa. Gábor Holló: Consultant for Aerie, Santen; honoraria from Aerie, Santen, Mundipharma. Luciano Quaranta: Editorial board member for Advances in Therapy; honoraria and consultancy: Allergan, Novartis, Omikron, Santen, Visufarma. Miguel A. Teus: Editorial board member for Advances in Therapy; research support from Alcon Vision, Laboratoires Théa, CareGroup, Novartis, Johnson \& Johnson Surgical Vision; honoraria from Alcon Vision, Allergan, CareGroup, Novartis, Santen, Glaukos. Hannu Uusitalo: Research grants, honoraria and membership of advisory boards: Alcon, Allergan, Bayer, Experimentica Herantis Pharma, MSD, Orion, Novartis, Pfizer, Roche, Santen, Shire, Thea. Norbert Pfeiffer: Honoraria and research support from Allergan,
Ivantis Inc, MicroOptx, Implandata, Sensimed, Thea, Santen, Pfizer. L. Jay Katz: Grants and research support from Allergan, Diopsys, Heidelberg Engineering, Alcon, Zeiss, Olleyes; consultant/advisory board: Olleyes (stock options); honoraria from Allergan, Glaukos, Bausch \& Lomb; Stock shareholder: Glaukos, Mati Therapeutics, Aerie, Olleyes; employment (salary): Glaukos (Chief Medical Officer). Leopold Schmetterer and Cindy M.L. Hutnik have nothing to declare.

Compliance with Ethics Guidelines. This article is based on previously conducted studies and does not contain any studies with human participants or animals performed by any of the authors.

Data Availability. Data sharing is not applicable to this article as no datasets were generated or analyzed during the current study.

Open Access. This article is licensed under a Creative Commons Attribution-NonCommercial 4.0 International License, which permits any non-commercial use, sharing, adaptation, distribution and reproduction in any medium or format, as long as you give appropriate credit to the original author(s) and the source, provide a link to the Creative Commons licence, and indicate if changes were made. The images or other third party material in this article are included in the article's Creative Commons licence, unless indicated otherwise in a credit line to the material. If material is not included in the article's Creative Commons licence and your intended use is not permitted by statutory regulation or exceeds the permitted use, you will need to obtain permission directly from the copyright holder. To view a copy of this licence, visit http://creativecommons.org/licenses/by$\mathrm{nc} / 4.0 /$.

\section{REFERENCES}

1. Fechtner RD, Realini T. Fixed combinations of topical glaucoma medications. Curr Opin Ophthalmol. 2004;15:132-5. 
2. Khouri AS, Realini T, Fechtner RD. Use of fixed-dose combination drugs for the treatment of glaucoma. Drugs Aging. 2007;24:1007-16.

3. Higginbotham EJ. Considerations in glaucoma therapy: fixed combinations versus their component medications. Clin Ophthalmol. 2010;4:1-9.

4. Hommer A. Role of fixed combinations in the management of open-angle glaucoma. Expert Rev Pharmacoecon Outcomes Res. 2011;11:91-9.

5. Holló G, Topouzis F, Fechtner RD. Fixed-combination intraocular pressure-lowering therapy for glaucoma and ocular hypertension: advantages in clinical practice. Expert Opin Pharmacother. 2014;15:1737-47.

6. Machen L, Razeghinejad R, Myers JS. Fixed-combination topical anti-hypertensive ophthalmic agents. Expert Opin Pharmacother. 2020;29:1-14.

7. Connor AJ, Fraser SG. Glaucoma prescribing trends in England 2000 to 2012. Eye (Lond). 2014;28: 863-9.

8. Bangalore S, Kamalakkannan G, Parkar S, Messerli FH. Fixed-dose combinations improve medication compliance: a meta-analysis. Am J Med. 2007;120: 713-9.

9. Gupta AK, Arshad S, Poulter NR. Compliance, safety, and effectiveness of fixed-dose combinations of antihypertensive agents: a meta-analysis. Hypertension. 2010;55:399-407.

10. Konstas A, Quaranta L, Katsanos A, Voudouragkaki I, Dutton G. Fixed combination therapies in glaucoma. In: Shaarawy T, Sherwood M, Hitchings R, Crowston J, editors. Glaucoma. 2nd ed. Amsterdam: Elsevier; 2015. p. 583-92.

11. Schwartz GF. Compliance and persistency in glaucoma follow-up treatment. Curr Opin Ophthalmol. 2005;16:114-21.

12. Connor J, Rafter N, Rodgers A. Do fixed-dose combination pills or unit-of-use packaging improve adherence? A systematic review. Bull World Health Organ. 2004;82:935-9.

13. Shin DH, Feldman RM, Sheu W-P. Fixed Combination Latanoprost/Timolol Study Group. Efficacy and safety of the fixed combinations latanoprost/timolol versus dorzolamide/timolol in patients with elevated intraocular pressure. Ophthalmology. 2004;111:276-82.

14. Konstas AGP, Quaranta L, Realini T. Overview of the [corrected] travoprost /timolol BAK-free fixed combination. Expert Opin Pharmacother. 2012;13: 757-66.
15. Barnebey HS, Robin AL. Adherence to fixed-combination versus unfixed travoprost $0.004 \%$ /timolol 0 . 5\% for glaucoma or ocular hypertension: a randomized trial. Am J Ophthalmol. 2017;176:61-9.

16. Holló G, Katsanos A, Boboridis KG, Irkec M, Konstas AGP. Preservative-free prostaglandin analogs and prostaglandin/timolol fixed combinations in the treatment of glaucoma: efficacy, safety and potential advantages. Drugs. 2018;78:39-64.

17. Hutzelmann J, Owens S, Shedden A, Adamsons I, Vargas E. Comparison of the safety and efficacy of the fixed combination of dorzolamide/timolol and the concomitant administration of dorzolamide and timolol: a clinical equivalence study. International Clinical Equivalence Study Group. Br J Ophthalmol. 1998;82:1249-53.

18. Boyle JE, Ghosh K, Gieser DK, Adamsons IA. A randomized trial comparing the dorzolamide-timolol combination given twice daily to monotherapy with timolol and dorzolamide. Dorzolamide-Timolol Study Group. Ophthalmology. 1998;105:1945-51.

19. Clineschmidt CM, Williams RD, Snyder E, Adamsons IA. A randomized trial in patients inadequately controlled with timolol alone comparing the dorzolamide-timolol combination to monotherapy with timolol or dorzolamide. Dorzolamide-Timolol Combination Study Group. Ophthalmology. 1998;105:1952-9.

20. Strohmaier K, Snyder E, DuBiner H, Adamsons I. The efficacy and safety of the dorzolamide-timolol combination versus the concomitant administration of its components. Dorzolamide-Timolol Study Group. Ophthalmology. 1998;105:1936-44.

21. Francis BA, Du LT, Berke S, Ehrenhaus M, Minckler DS, Cosopt Study Group. Comparing the fixed combination dorzolamide-timolol (Cosopt) to concomitant administration of $2 \%$ dorzolamide (Trusopt) and $0.5 \%$ timolol-a randomized controlled trial and a replacement study. J Clin Pharm Ther. 2004;29:375-80.

22. Ormrod D, McClellan K. Topical dorzolamide $2 \% /$ timolol $0.5 \%$ : a review of its use in the treatment of open-angle glaucoma. Drugs Aging. 2000;17:477-96.

23. Konstas AGP, Quaranta L, Yan DB, et al. Twentyfour hour efficacy with the dorzolamide/timololfixed combination compared with the brimonidine/timolol-fixed combination in primary openangle glaucoma. Eye (Lond). 2012;26:80-7.

24. Katz LJ. Modern alchemy: fixed combinations of glaucoma drugs. Am J Ophthalmol. 2005;140: 125-6. 
25. Yeh J, Kravitz D, Francis B. Rational use of the fixed combination of dorzolamide-timolol in the management of raised intraocular pressure and glaucoma. Clin Ophthalmol. 2008;2:389-99.

26. Aptel F, Cucherat M, Denis P. Efficacy and tolerability of prostaglandin-timolol fixed combinations: a meta-analysis of randomized clinical trials. Eur J Ophthalmol. 2012;22:5-18.

27. Internal calculations by Santen via IQVIA database: MIDAS all European panels in ATC S1E2, MAT 2019 in Standard Units

28. Razeghinejad MR, Sawchyn AK, Katz LJ. Fixed combinations of dorzolamide-timolol and brimonidine-timolol in the management of glaucoma. Expert Opin Pharmacother. 2010;11:959-68.

29. Frampton JE, Perry CM. Topical dorzolamide $2 \% /$ timolol $0.5 \%$ ophthalmic solution: a review of its use in the treatment of glaucoma and ocular hypertension. Drugs Aging. 2006;23:977-95.

30. Choudhri S, Wand M, Shields MB. A comparison of dorzolamide-timolol combination versus the concomitant drugs. Am J Ophthalmol. 2000;130:832-3.

31. Konstas AGP, Bányai L, Blask K-D, et al. Intraocular pressure and safety in glaucoma patients switching to latanoprost/timolol maleate fixed combination from mono- and adjunctive therapies. J Ocul Pharmacol Ther. 2004;20:375-82.

32. Bacharach J, Delgado MF, Iwach AG. Comparison of the efficacy of the fixed-combination timolol/dorzolamide versus concomitant administration of timolol and dorzolamide. J Ocul Pharmacol Ther. 2003;19:93-6.

33. Konstas AGP, Kozobolis VP, Tersis I, Leech J, Stewart WC. The efficacy and safety of the timolol/dorzolamide fixed combination vs latanoprost in exfoliation glaucoma. Eye (Lond). 2003;17:41-6.

34. Henderer JD, Wilson RP, Moster MR, et al. Timolol/dorzolamide combination therapy as initial treatment for intraocular pressure over 30 mmHg. J Glaucoma. 2005;14:267-70.

35. Hutnik C, Neima D, Ibrahim F, et al. Tolerability and effectiveness of preservative-free dorzolamidetimolol (preservative-free COSOPT) in patients with open-angle glaucoma or ocular hypertension. Clin Ophthalmol. 2010;4:581-90.

36. Giles TD. Rationale for combination therapy as initial treatment for hypertension. J Clin Hypertens (Greenwich). 2003;5:4-11.

37. Petrilla AA, Benner JS, Battleman DS, Tierce JC, Hazard EH. Evidence-based interventions to improve patient compliance with antihypertensive and lipid-lowering medications. Int $\mathrm{J}$ Clin Pract. 2005;59:1441-51.

38. Neutel JM, Smith DHG. Improving patient compliance: a major goal in the management of hypertension. J Clin Hypertens (Greenwich). 2003;5: 127-32.

39. Shedden A, Adamsons IA, Getson AJ, et al. Comparison of the efficacy and tolerability of preservative-free and preservative-containing formulations of the dorzolamide/timolol fixed combination $\left(\mathrm{COSOPT}^{\mathrm{TM}}\right)$ in patients with elevated intraocular pressure in a randomized clinical trial. Graefes Arch Clin Exp Ophthalmol. 2010;248:1757-64.

40. Konstas AG, Boboridis KG, Kapis P, et al. 24-hour efficacy and ocular surface health with preservativefree tafluprost alone and in conjunction with preservative-free dorzolamide/timolol fixed combination in open-angle glaucoma patients insufficiently controlled with preserved latanoprost monotherapy. Adv Ther. 2017;34:221-35.

41. Renieri G, Führer K, Scheithe K, Lorenz K, Pfeiffer N, Thieme H. Efficacy and tolerability of preservativefree eye drops containing a fixed combination of dorzolamide and timolol in glaucoma patients. J Ocul Pharmacol Ther. 2010;26:597-603.

42. Abegão Pinto L, Vandewalle E, Gerlier L, Stalmans I, CosoptUD Switch Study Group. Improvement in glaucoma patient quality of life by therapy switch to preservative-free timolol/dorzolamide fixed combination. Ophthalmologica. 2014;231:166-71.

43. Lorenz K, Wasielica-Poslednik J, Bell K, et al. Efficacy and safety of preoperative IOP reduction using a preservative-free fixed combination of dorzolamide/timolol eye drops versus oral acetazolamide and dexamethasone eye drops and assessment of the clinical outcome of trabeculectomy in glaucoma. PLoS One. 2017;12:e0171636.

44. Denis P, Duch S, Chen E, et al. European real-world data about the use of a new delivery system containing a preservative-free multi-dose glaucoma treatment. Eur J Ophthalmol. 2020. https://doi.org/ $10.1177 / 1120672120919342$.

45. Nemera. Novelia ${ }^{\circledR}$. Using intelligent design to deliver safe preservative free multi-dose eye drops. https://www.nemera.net/wp-content/uploads/ 2014/06/WP-Novelia-alternativetofilters-June2015. pdf. Accessed 19 Oct 2020.

46. Baudouin C. Detrimental effect of preservatives in eyedrops: implications for the treatment of glaucoma. Acta Ophthalmol. 2008;86:716-26. 
47. Fechtner RD, Godfrey DG, Budenz D, Stewart JA, Stewart WC, Jasek MC. Prevalence of ocular surface complaints in patients with glaucoma using topical intraocular pressure-lowering medications. Cornea. 2010;29:618-21.

48. Baudouin C, Labbé A, Liang H, Pauly A, BrignoleBaudouin F. Preservatives in eyedrops: the good, the bad and the ugly. Prog Retin Eye Res. 2010;29: 312-34.

49. Konstas AGP, Holló G. Preservative-free tafluprost/timolol fixed combination: a new opportunity in the treatment of glaucoma. Expert Opin Pharmacother. 2016;17:1271-83.

50. Oddone F, Tanga L, Kóthy P, Holló G, VISIONARY Study Group. Treatment of open-angle glaucoma and ocular hypertension with preservative-free tafluprost/timolol fixed-dose combination therapy: The VISIONARY Study. Adv Ther. 2020;37:1436-51.

51. Macdonald ECA, Lockington D, Roberts F, Tetley L, Ramaesh K. Unit-dose dispenser tips: a potential source of ocular injury. Br J Ophthalmol. 2010;94: 136-7.

52. Dietlein TS, Jordan JF, Lüke C, Schild A, Dinslage S, Krieglstein GK. Self-application of single-use eyedrop containers in an elderly population: comparisons with standard eyedrop bottle and with younger patients. Acta Ophthalmol. 2008;86:856-9.

53. Parkkari M, Latvala T, Ropo A. Handling test of eye drop dispenser-comparison of unit-dose pipettes with conventional eye drop bottles. J Ocul Pharmacol Ther. 2010;26:273-6.

54. Uusitalo H, Pillunat LE, Ropo A, Phase III Study Investigators. Efficacy and safety of tafluprost 0 . 0015\% versus latanoprost $0.005 \%$ eye drops in open-angle glaucoma and ocular hypertension: 24-month results of a randomized, double-masked phase III study. Acta Ophthalmol. 2010;88:12-9.

55. Day DG, Walters TR, Schwartz GF, et al. Bimatoprost $0.03 \%$ preservative-free ophthalmic solution versus bimatoprost $0.03 \%$ ophthalmic solution (Lumigan) for glaucoma or ocular hypertension: a 12-week, randomised, double-masked trial. $\mathrm{Br} \mathrm{J}$ Ophthalmol. 2013;97:989-93.

56. Stalmans I, Oddone F, Cordeiro MF, et al. Comparison of preservative-free latanoprost and preservative-free bimatoprost in a multicenter, randomized, investigator-masked cross-over clinical trial, the SPORT trial. Graefes Arch Clin Exp Ophthalmol. 2016;254:1151-8.

57. Wistrand PJ. Carbonic anhydrase in the anterior uvea of the rabbit. Acta Physiol Scand. 1951;24: 145-8.
58. Becker B. Decrease in intraocular pressure in man by a carbonic anhydrase inhibitor, diamox; a preliminary report. Am J Ophthalmol. 1954;37:13-5.

59. Maren TH. Carbonic anhydrase: chemistry, physiology, and inhibition. Physiol Rev. 1967;47: 595-781.

60. Maren TH, Jankowska L, Sanyal G, Edelhauser HF. The transcorneal permeability of sulfonamide carbonic anhydrase inhibitors and their effect on aqueous humor secretion. Exp Eye Res. 1983;36: 457-79.

61. Sugrue MF, Mallorga P, Schwam H, Baldwin JJ, Ponticello GS. Preclinical studies on L-671,152, a topically effective ocular hypotensive carbonic anhydrase inhibitor. $\mathrm{Br} \mathrm{J}$ Pharmacol. 1989;98(Suppl):820P.

62. Wang RF, Serle JB, Podos SM, Sugrue MF. The ocular hypotensive effect of the topical carbonic anhydrase inhibitor L-671,152 in glaucomatous monkeys. Arch Ophthalmol. 1990;108:511-3.

63. Maus TL, Larsson LI, McLaren JW, Brubaker RF. Comparison of dorzolamide and acetazolamide as suppressors of aqueous humor flow in humans. Arch Ophthalmol. 1997;115:45-9.

64. Larsson LI, Alm A. Aqueous humor flow in human eyes treated with dorzolamide and different doses of acetazolamide. Arch Ophthalmol. 1998;116:19-24.

65. Wayman L, Larsson LI, Maus T, Alm A, Brubaker R. Comparison of dorzolamide and timolol as suppressors of aqueous humor flow in humans. Arch Ophthalmol. 1997;115:1368-71.

66. Topper JE, Brubaker RF. Effects of timolol, epinephrine, and acetazolamide on aqueous flow during sleep. Invest Ophthalmol Vis Sci. 1985;26: 1315-9.

67. Vanlandingham BD, Maus TL, Brubaker RF. The effect of dorzolamide on aqueous humor dynamics in normal human subjects during sleep. Ophthalmology. 1998;105:1537-40.

68. Zimmerman TJ, Kaufman HE. Timolol. A betaadrenergic blocking agent for the treatment of glaucoma. Arch Ophthalmol. 1977;95:601-4.

69. Zimmerman TJ, Kass MA, Yablonski ME, Becker B. Timolol maleate: efficacy and safety. Arch Ophthalmol. 1979;97:656-8.

70. Uusitalo H, Niño J, Tahvanainen K, et al. Efficacy and systemic side-effects of topical $0.5 \%$ timolol aqueous solution and $0.1 \%$ timolol hydrogel. Acta Ophthalmol Scand. 2005;83:723-8. 
71. Quaranta L, Katsanos A, Floriani I, Riva I, Russo A, Konstas AGP. Circadian intraocular pressure and blood pressure reduction with timolol $0.5 \%$ solution and timogel $0.1 \%$ in patients with primary open-angle glaucoma. J Clin Pharmacol. 2012;52: 1552-7.

72. Konstas AG, Mantziris DA, Maltezos A, Cate EA, Stewart WC. Comparison of 24 hour control with Timoptic $0.5 \%$ and Timoptic-XE $0.5 \%$ in exfoliation and primary open-angle glaucoma. Acta Ophthalmol Scand. 1999;77:541-3.

73. Konstas AG, Mantziris DA, Cate EA, Stewart WC. Effect of timolol on the diurnal intraocular pressure in exfoliation and primary open-angle glaucoma. Arch Ophthalmol. 1997;115:975-9.

74. European Glaucoma Society. Terminology and guidelines for glaucoma. 4th ed. Savona: PubliComm; 2014.

75. Li T, Lindsley K, Rouse B, et al. Comparative effectiveness of first-line medications for primary openangle glaucoma: a systematic review and network meta-analysis. Ophthalmology. 2016;123:129-40.

76. Doyle WJ, Weber PA, Meeks RH. Effect of topical timolol maleate on exercise performance. Arch Ophthalmol. 1984;102:1517-8.

77. Fraunfelder FT, Barker AF. Respiratory effects of timolol. N Engl J Med. 1984;311:1441.

78. Nelson WL, Fraunfelder FT, Sills JM, Arrowsmith JB, Kuritsky JN. Adverse respiratory and cardiovascular events attributed to timolol ophthalmic solution, 1978-1985. Am J Ophthalmol. 1986;102:606-11.

79. Niño J, Tahvanainen $\mathrm{K}$, Uusitalo $\mathrm{H}$, et al. Cardiovascular effects of ophthalmic $0.5 \%$ timolol aqueous solution and $0.1 \%$ timolol hydrogel. Clin Physiol Funct Imaging. 2002;22:271-8.

80. Nieminen T, Uusitalo $H$, Mäenpää J, et al. Polymorphisms of genes CYP2D6, ADRB1 and GNAS1 in pharmacokinetics and systemic effects of ophthalmic timolol. A pilot study. Eur J Clin Pharmacol. 2005;61:811-9.

81. Konstas AG, Maltezos A, Bufidis T, Hudgins AG, Stewart WC. Twenty-four hour control of intraocular pressure with dorzolamide and timolol maleate in exfoliation and primary open-angle glaucoma. Eye (Lond). 2000;14:73-7.

82. Konstas AGP, Papapanos P, Tersis I, Houliara D, Stewart WC. Twenty-four-hour diurnal curve comparison of commercially available latanoprost 0 . $005 \%$ versus the timolol and dorzolamide fixed combination. Ophthalmology. 2003;110:1357-60.
83. Konstas AGP, Kozobolis VP, Tsironi S, Makridaki I, Efremova R, Stewart WC. Comparison of the 24-hour intraocular pressure-lowering effects of latanoprost and dorzolamide/timolol fixed combination after 2 and 6 months of treatment. Ophthalmology. 2008;115:99-103.

84. Shemesh G, Moisseiev E, Lazar M, Kurtz S. Intraocular pressure reduction of fixed combination timolol maleate $0.5 \%$ and dorzolamide $2 \%$ (Cosopt) administered three times a day. Clin Ophthalmol. $2012 ; 6: 283-7$.

85. Kim T-W, Kim M, Lee EJ, Jeoung JW, Park KH. Intraocular pressure-lowering efficacy of dorzolamide/timolol fixed combination in normal-tension glaucoma. J Glaucoma. 2014;23:329-32.

86. Hatanaka M, Reis A, Sano ME, Susanna R. Additive intraocular pressure reduction effect of fixed combination of maleate timolol $0.5 \%$ /dorzolamide $2 \%$ (Cosopt) on monotherapy with latanoprost (Xala$\tan )$ in patients with elevated intraocular pressure: a prospective, 4-week, open-label, randomized, controlled clinical trial. J Glaucoma. 2010;19:331-5.

87. Sezgin Akçay Bİ, Güney E, Bozkurt KT, Unlü C, Akçali G. The safety and efficacy of brinzolamide $1 \% /$ timolol $0.5 \%$ fixed combination versus dorzolamide $2 \% /$ timolol $0.5 \%$ in patients with open-angle glaucoma or ocular hypertension. J Ocul Pharmacol Ther. 2013;29:882-6.

88. Aihara M, Adachi M, Matsuo $\mathrm{H}$, et al. Additive effects and safety of fixed combination therapy with $1 \%$ brinzolamide and $0.5 \%$ timolol versus $1 \%$ dorzolamide and $0.5 \%$ timolol in prostaglandin-treated glaucoma patients. Acta Ophthalmol. 2017;95: e720-6.

89. Budengeri P, Cheng J-W, Cai J-P, Wei R-L. Efficacy and tolerability of fixed combination of brimonidine $0.2 \% /$ timolol $0.5 \%$ compared with fixed combination of dorzolamide $2 \% /$ timolol $0.5 \%$ in the treatment of patients with elevated intraocular pressure: a meta-analysis of randomized controlled trials. J Ocul Pharmacol Ther. 2013;29:474-9.

90. Seymenoğlu G, Baser EF, Öztürk B, Gülhan C. Comparison of dorzolamide/timolol versus brimonidine/timolol fixed combination therapy in the management of steroid-induced ocular hypertension. J Glaucoma. 2015;24:111-6.

91. Miglior S, Grunden JW, Kwok K, Xalacom/Cosopt European Study Group. Efficacy and safety of fixed combinations of latanoprost/timolol and dorzolamide/timolol in open-angle glaucoma or ocular hypertension. Eye (Lond). 2010;24:1234-42.

92. Fechtner RD, Airaksinen PJ, Getson AJ, Lines CR, Adamsons IA, COSOPT versus XALATAN Study 
Groups. Efficacy and tolerability of the dorzolamide $2 \% /$ timolol $0.5 \%$ combination (COSOPT) versus 0 . $005 \%$ (XALATAN) in the treatment of ocular hypertension or glaucoma: results from two randomized clinical trials. Acta Ophthalmol Scand. 2004;82:42-8.

93. Teus MA, Miglior S, Laganovska G, et al. Efficacy and safety of travoprost/timolol vs dorzolamide/timolol in patients with open-angle glaucoma or ocular hypertension. Clin Ophthalmol. 2009;3: 629-36.

94. Coleman AL, Lerner F, Bernstein P, Whitcup SM. A 3-month randomized controlled trial of bimatoprost (LUMIGAN) versus combined timolol and dorzolamide (Cosopt) in patients with glaucoma or ocular hypertension. Ophthalmology. 2003;110: 2362-8.

95. Rainer G, Menapace R, Findl O, Petternel V, Kiss B, Georgopoulos M. Intraindividual comparison of the effects of a fixed dorzolamide-timolol combination and latanoprost on intraocular pressure after small incision cataract surgery. J Cataract Refract Surg. 2001;27:706-10.

96. Wilensky JT. The role of diurnal pressure measurements in the management of open angle glaucoma. Curr Opin Ophthalmol. 2004;15:90-2.

97. Wax MB, Camras CB, Fiscella RG, Girkin C, Singh K, Weinreb RN. Emerging perspectives in glaucoma: optimizing 24-hour control of intraocular pressure. Am J Ophthalmol. 2002;133(Suppl):S1-10.

98. Asrani S, Zeimer R, Wilensky J, Gieser D, Vitale S, Lindenmuth K. Large diurnal fluctuations in intraocular pressure are an independent risk factor in patients with glaucoma. J Glaucoma. 2000;9: $134-42$.

99. Orzalesi N, Rossetti L, Invernizzi T, Bottoli A, Autelitano A. Effect of timolol, latanoprost, and dorzolamide on circadian IOP in glaucoma or ocular hypertension. Invest Ophthalmol Vis Sci. 2000;41:2566-73.

100. Liu JHK, Weinreb RN. Monitoring intraocular pressure for 24 h. Br J Ophthalmol. 2011;95:599-600.

101. Konstas AG, Kahook MY, Araie M, et al. Diurnal and 24-h intraocular pressures in glaucoma: monitoring strategies and impact on prognosis and treatment. Adv Ther. 2018;35:1775-804.

102. Hughes E, Spry P, Diamond J. 24-hour monitoring of intraocular pressure in glaucoma management: a retrospective review. J Glaucoma. 2003;12:232-6.

103. Aptel F, Weinreb RN, Chiquet C, Mansouri K. 24-h monitoring devices and nyctohemeral rhythms of intraocular pressure. Prog Retin Eye Res. 2016;55: $108-48$.

104. Konstas AGP, Quaranta L, Bozkurt B, et al. 24-h efficacy of glaucoma treatment options. Adv Ther. 2016;33:481-517.

105. Quaranta L, Katsanos A, Russo A, Riva I. 24-hour intraocular pressure and ocular perfusion pressure in glaucoma. Surv Ophthalmol. 2013;58:26-41.

106. Quaranta L, Konstas AGP, Rossetti L, et al. Untreated 24-h intraocular pressures measured with Goldmann applanation tonometry vs nighttime supine pressures with Perkins applanation tonometry. Eye (Lond). 2010;24:1252-8.

107. Konstas AGP, Katsanos A, Quaranta L, Mikropoulos DG, Tranos PG, Teus MA. Twenty-four hour efficacy of glaucoma medications. Prog Brain Res. 2015;221: 297-318.

108. Sheybani A, Scott R, Samuelson TW, et al. Openangle glaucoma: burden of illness, current therapies, and the management of nocturnal IOP variation. Ophthalmol Ther. 2020;9:1-14.

109. Barkana Y, Anis S, Liebmann J, Tello C, Ritch R. Clinical utility of intraocular pressure monitoring outside of normal office hours in patients with glaucoma. Arch Ophthalmol. 2006;124:793-7.

110. Liu JH, Kripke DF, Hoffman RE, et al. Nocturnal elevation of intraocular pressure in young adults. Invest Ophthalmol Vis Sci. 1998;39:2707-12.

111. Stewart WC, Konstas AGP, Nelson LA, Kruft B. Meta-analysis of 24-hour intraocular pressure studies evaluating the efficacy of glaucoma medicines. Ophthalmology. 2008;115(1117-1122):e1.

112. Orzalesi N, Rossetti L, Bottoli A, Fumagalli E, Fogagnolo P. The effect of latanoprost, brimonidine, and a fixed combination of timolol and dorzolamide on circadian intraocular pressure in patients with glaucoma or ocular hypertension. Arch Ophthalmol. 2003;121:453-7.

113. Konstas AGP, Mikropoulos D, Dimopoulos AT, Moumtzis G, Nelson LA, Stewart WC. Second-line therapy with dorzolamide/timolol or latanoprost/timolol fixed combination versus adding dorzolamide/timolol fixed combination to latanoprost monotherapy. $\mathrm{Br} \mathrm{J}$ Ophthalmol. 2008;92:1498-502.

114. Quaranta L, Miglior S, Floriani I, Pizzolante T, Konstas AGP. Effects of the timolol-dorzolamide fixed combination and latanoprost on circadian diastolic ocular perfusion pressure in glaucoma. Invest Ophthalmol Vis Sci. 2008;49:4226-31. 
115. Feldman RM, Stewart RH, Stewart WC, Jia G, Smugar SS, Galet VA. 24-hour control of intraocular pressure with $2 \%$ dorzolamide $/ 0.5 \%$ timolol fixedcombination ophthalmic solution in open-angle glaucoma. Curr Med Res Opin. 2008;24:2403-12.

116. Eren MH, Gungel H, Altan C, Pasaoglu IB, Sabanci S. Comparison of dorzolamide/timolol and latanoprost/timolol fixed combinations on diurnal intraocular pressure control in primary open-angle glaucoma. J Ocul Pharmacol Ther. 2012;28:381-6.

117. Konstas AG, Maltezos AC, Gandi S, Hudgins AC, Stewart WC. Comparison of 24-hour intraocular pressure reduction with two dosing regimens of latanoprost and timolol maleate in patients with primary open-angle glaucoma. Am J Ophthalmol. 1999;128:15-20.

118. Liu JHK, Kripke DF, Weinreb RN. Comparison of the nocturnal effects of once-daily timolol and latanoprost on intraocular pressure. Am J Ophthalmol. 2004;138:389-95.

119. Quaranta L, Gandolfo F, Turano R, et al. Effects of topical hypotensive drugs on circadian IOP, blood pressure, and calculated diastolic ocular perfusion pressure in patients with glaucoma. Invest Ophthalmol Vis Sci. 2006;47:2917-23.

120. Coakes RL, Brubaker RF. The mechanism of timolol in lowering intraocular pressure: in the normal eye. Arch Ophthalmol. 1978;96:2045-8.

121. Brubaker RF. Flow of aqueous humor in humans [The Friedenwald Lecture]. Invest Ophthalmol Vis Sci. 1991;32:3145-66.

122. Reiss GR, Lee DA, Topper JE, Brubaker RF. Aqueous humor flow during sleep. Invest Ophthalmol Vis Sci. 1984;25:776-8.

123. Toris CB, Zhan G-L, Yablonski ME, Camras CB. Effects on aqueous flow of dorzolamide combined with either timolol or acetazolamide. J Glaucoma. $2004 ; 13: 210-5$.

124. Konstas AGP, Kozobolis VP, Lallos N, Christodoulakis E, Stewart JA, Stewart WC. Daytime diurnal curve comparison between the fixed combinations of latanoprost $0.005 \% /$ timolol maleate $0.5 \%$ and dorzolamide $2 \% /$ timolol maleate $0.5 \%$. Eye (Lond). 2004;18:1264-9.

125. Konstas AG, Stewart WC, Topouzis F, Tersis I, Holmes KT, Stangos NT. Brimonidine $0.2 \%$ given two or three times daily versus timolol maleate 0 . $5 \%$ in primary open-angle glaucoma. Am J Ophthalmol. 2001;131:729-33.

126. Liu JHK, Medeiros FA, Slight JR, Weinreb RN. Diurnal and nocturnal effects of brimonidine monotherapy on intraocular pressure. Ophthalmology. 2010;117:2075-9.

127. Ehrenreich DL, Burns RA, Alman RW, Fazekas JF. Influence of acetazolamide on cerebral blood flow. Arch Neurol. 1961;5:227-32.

128. Cotev S, Lee J, Severinghaus JW. The effects of acetazolamide on cerebral blood flow and cerebral tissue PO2. Anesthesiology. 1968;29:471-7.

129. Laux BE, Raichle ME. The effect of acetazolamide on cerebral blood flow and oxygen utilization in the rhesus monkey. J Clin Invest. 1978;62:585-92.

130. Bill A. Effects of acetazolamide and carotid occlusion on the ocular blood flow in unanesthetized rabbits. Invest Ophthalmol. 1974;13:954-8.

131. Dallinger S, Bobr B, Findl O, Eichler HG, Schmetterer L. Effects of acetazolamide on choroidal blood flow. Stroke. 1998;29:997-1001.

132. Kiss B, Dallinger S, Findl O, Rainer G, Eichler HG, Schmetterer L. Acetazolamide-induced cerebral and ocular vasodilation in humans is independent of nitric oxide. Am J Physiol. 1999;276:R1661-1667.

133. Schmidl D, Garhofer G, Schmetterer L. The complex interaction between ocular perfusion pressure and ocular blood flow - relevance for glaucoma. Exp Eye Res. 2011;93(2):141-55.

134. Balfour JA, Wilde MI. Dorzolamide. A review of its pharmacology and therapeutic potential in the management of glaucoma and ocular hypertension. Drugs Aging. 1997;10:384-403.

135. Sugrue MF. Pharmacological and ocular hypotensive properties of topical carbonic anhydrase inhibitors. Prog Retin Eye Res. 2000;19:87-112.

136. Kadam RS, Jadhav G, Ogidigben M, Kompella UB. Ocular pharmacokinetics of dorzolamide and brinzolamide after single and multiple topical dosing: implications for effects on ocular blood flow. Drug Metab Dispos. 2011;39:1529-37.

137. Josefsson A, Sigurdsson SB, Bang K, Eysteinsson T. Dorzolamide induces vasodilatation in isolated precontracted bovine retinal arteries. Exp Eye Res. 2004;78:215-21.

138. Kehler AK, Holmgaard K, Hessellund A, Aalkjaer C, Bek T. Variable involvement of the perivascular retinal tissue in carbonic anhydrase inhibitor induced relaxation of porcine retinal arterioles in vitro. Invest Ophthalmol Vis Sci. 2007;48: 4688-93.

139. Kringelholt S, Simonsen U, Bek T. Dorzolamide-induced relaxation of intraocular porcine ciliary 
arteries in vitro depends on nitric oxide and the vascular endothelium. Curr Eye Res. 2012;37: 1107-13.

140. El-Galaly A, Aalkjaer C, Kringelholt SK, Misfeldt MW, Bek T. Dorzolamide-induced relaxation of porcine retinal arterioles in vitro depends on nitric oxide but not on acidosis in vascular smooth muscle cells. Exp Eye Res. 2014;128:67-72.

141. Schmidt KG, von Rückmann A, Pillunat LE. Topical carbonic anhydrase inhibition increases ocular pulse amplitude in high tension primary open angle glaucoma. Br J Ophthalmol. 1998;82:758-62.

142. Fuchsjäger-Mayrl G, Wally B, Rainer G, et al. Effect of dorzolamide and timolol on ocular blood flow in patients with primary open angle glaucoma and ocular hypertension. Br J Ophthalmol. 2005;89: 1293-7.

143. Costagliola C, Campa C, Parmeggiani F, et al. Effect of $2 \%$ dorzolamide on retinal blood flow: a study on juvenile primary open-angle glaucoma patients already receiving $0.5 \%$ timolol. Br J Clin Pharmacol. 2007;63:376-9.

144. Siesky B, Harris A, Cantor LB, et al. A comparative study of the effects of brinzolamide and dorzolamide on retinal oxygen saturation and ocular microcirculation in patients with primary openangle glaucoma. Br J Ophthalmol. 2008;92:500-4.

145. Faingold D, Hudson C, Flanagan J, et al. Assessment of retinal hemodynamics with the Canon laser blood flowmeter after a single dose of $2 \%$ dorzolamide hydrochloride eyedrops. Can J Ophthalmol. 2004;39:506-10.

146. Harris A, Arend O, Arend S, Martin B. Effects of topical dorzolamide on retinal and retrobulbar hemodynamics. Acta Ophthalmol Scand. 1996;74: 569-72.

147. Harris A, Arend O, Kagemann L, Garrett M, Chung HS, Martin B. Dorzolamide, visual function and ocular hemodynamics in normal-tension glaucoma. J Ocul Pharmacol Ther. 1999;15:189-97.

148. Harris A, Arend O, Chung HS, Kagemann L, Cantor L, Martin B. A comparative study of betaxolol and dorzolamide effect on ocular circulation in normaltension glaucoma patients. Ophthalmology. 2000;107:430-4.

149. Arend O, Harris A, Wolter P, Remky A. Evaluation of retinal haemodynamics and retinal function after application of dorzolamide, timolol and latanoprost in newly diagnosed open-angle glaucoma patients. Acta Ophthalmol Scand. 2003;81:474-9.
150. Martinez A, Gonzalez F, Capeans C, Perez R, Sanchez-Salorio M. Dorzolamide effect on ocular blood flow. Invest Ophthalmol Vis Sci. 1999;40:1270-5.

151. Avunduk AM, Sari A, Akyol N, et al. The one-month effects of topical betaxolol, dorzolamide and apraclonidine on ocular blood flow velocities in patients with newly diagnosed primary open-angle glaucoma. Ophthalmologica. 2001;215:361-5.

152. Galassi F, Sodi A, Renieri G, et al. Effects of timolol and dorzolamide on retrobulbar hemodynamics in patients with newly diagnosed primary open-angle glaucoma. Ophthalmologica. 2002;216:123-8.

153. Harris A, Migliardi R, Rechtman E, Cole CN, Yee AB, Garzozi HJ. Comparative analysis of the effects of dorzolamide and latanoprost on ocular hemodynamics in normal tension glaucoma patients. Eur J Ophthalmol. 2003;13:24-31.

154. Zeitz O, Matthiessen ET, Reuss J, et al. Effects of glaucoma drugs on ocular hemodynamics in normal tension glaucoma: a randomized trial comparing bimatoprost and latanoprost with dorzolamide [ISRCTN18873428]. BMC Ophthalmol. 2005;5:6.

155. Bergstrand IC, Heijl A, Harris A. Dorzolamide and ocular blood flow in previously untreated glaucoma patients: a controlled double-masked study. Acta Ophthalmol Scand. 2002;80:176-82.

156. Fuchsjäger-Mayrl G, Wally B, Georgopoulos M, et al. Ocular blood flow and systemic blood pressure in patients with primary open-angle glaucoma and ocular hypertension. Invest Ophthalmol Vis Sci. 2004;45:834-9.

157. Fuchsjäger-Mayrl G, Georgopoulos M, Hommer A, et al. Effect of dorzolamide and timolol on ocular pressure: blood flow relationship in patients with primary open-angle glaucoma and ocular hypertension. Invest Ophthalmol Vis Sci. 2010;51: 1289-96.

158. Klemm M, Zeitz O, Reuss J, Matthiessen ET, Richard G. Therapy of normal tension glaucoma: effect of brinzolamide on ocular haemodynamics. Klin Monbl Augenheilkd. 2003;220:330-3.

159. Harris A, Jonescu-Cuypers CP, Kagemann L, et al. Effect of dorzolamide timolol combination versus timolol $0.5 \%$ on ocular bloodflow in patients with primary open-angle glaucoma. Am J Ophthalmol. 2001;132:490-5.

160. Janulevicienë I, Harris A, Kagemann L, Siesky B, McCranor L. A comparison of the effects of dorzolamide/timolol fixed combination versus latanoprost on intraocular pressure and pulsatile ocular blood flow in primary open-angle glaucoma patients. Acta Ophthalmol Scand. 2004;82:730-7. 
161. Uva MG, Longo A, Reibaldi M, Reibaldi A. The effect of timolol-dorzolamide and timolol-pilocarpine combinations on ocular blood flow in patients with glaucoma. Am J Ophthalmol. 2006;141:1158-60.

162. Siesky B, Harris A, Sines D, et al. A comparative analysis of the effects of the fixed combination of timolol and dorzolamide versus latanoprost plus timolol on ocular hemodynamics and visual function in patients with primary open-angle glaucoma. J Ocul Pharmacol Ther. 2006;22:353-61.

163. Martinez A, Sanchez M. Retrobulbar haemodynamic effects of the latanoprost/timolol and the dorzolamide/timolol fixed combinations in newly diagnosed glaucoma patients. Int J Clin Pract. 2007;61:815-25.

164. Januleviciene I, Ehrlich R, Siesky B, Nedzelskiené I, Harris A. Visual function, optic nerve structure, and ocular blood flow parameters after 1 year of glaucoma treatment with fixed combinations. Eur J Ophthalmol. 2009;19:790-7.

165. Harris A, Chung HS, Ciulla TA, Kagemann L. Progress in measurement of ocular blood flow and relevance to our understanding of glaucoma and agerelated macular degeneration. Prog Retin Eye Res. 1999;18:669-87.

166. Polska E, Kircher K, Ehrlich P, Vecsei PV, Schmetterer L. RI in central retinal artery as assessed by CDI does not correspond to retinal vascular resistance. Am J Physiol Heart Circ Physiol. 2001;280: H1442-1447.

167. Schmetterer L, Garhofer G. How can blood flow be measured? Surv Ophthalmol. 2007;52(Suppl 2): S134-138.

168. Stalmans I, Vandewalle E, Anderson DR, et al. Use of colour Doppler imaging in ocular blood flow research. Acta Ophthalmol. 2011;89:e609-630.

169. Wei X, Balne PK, Meissner KE, Barathi VA, Schmetterer L, Agrawal R. Assessment of flow dynamics in retinal and choroidal microcirculation. Surv Ophthalmol. 2018;63:646-64.

170. Kashani AH, Chen C-L, Gahm JK, et al. Optical coherence tomography angiography: a comprehensive review of current methods and clinical applications. Prog Retin Eye Res. 2017;60:66-100.

171. Spaide RF, Fujimoto JG, Waheed NK, Sadda SR, Staurenghi G. Optical coherence tomography angiography. Prog Retin Eye Res. 2018;64:1-55.

172. Ang M, Tan ACS, Cheung CMG, et al. Optical coherence tomography angiography: a review of current and future clinical applications. Graefes Arch Clin Exp Ophthalmol. 2018;256:237-45.
173. Chua J, Tan B, Ang M, et al. Future clinical applicability of optical coherence tomography angiography. Clin Exp Optom. 2019;102:260-9.

174. Werkmeister RM, Dragostinoff N, Palkovits S, et al. Measurement of absolute blood flow velocity and blood flow in the human retina by dual-beam bidirectional Doppler fourier-domain optical coherence tomography. Invest Ophthalmol Vis Sci. 2012;53:6062-71.

175. Doblhoff-Dier V, Schmetterer L, Vilser W, et al. Measurement of the total retinal blood flow using dual beam Fourier-domain Doppler optical coherence tomography with orthogonal detection planes. Biomed Opt Express. 2014;5:630-42.

176. Srinivas S, Tan $\mathrm{O}$, Wu S, et al. Measurement of retinal blood flow in normal Chinese-American subjects by Doppler Fourier-domain optical coherence tomography. Invest Ophthalmol Vis Sci. 2015;56:1569-74.

177. Huang S, Shen M, Zhu D, et al. In vivo imaging of retinal hemodynamics with OCT angiography and Doppler OCT. Biomed Opt Express. 2016;7:663-76.

178. Told R, Wang L, Cull G, et al. Total retinal blood flow in a nonhuman primate optic nerve transection model using dual-beam bidirectional Doppler FD-OCT and microsphere method. Invest Ophthalmol Vis Sci. 2016;57:1432-40.

179. Pechauer AD, Hwang TS, Hagag AM, et al. Assessing total retinal blood flow in diabetic retinopathy using multiplane en face Doppler optical coherence tomography. Br J Ophthalmol. 2018;102:126-30.

180. Tani T, Song Y-S, Yoshioka T, et al. Repeatability and reproducibility of retinal blood flow measurement using a Doppler optical coherence tomography flowmeter in healthy subjects. Invest Ophthalmol Vis Sci. 2017;58:2891-8.

181. Sakai J, Minamide KJ, Nakamura S, et al. Retinal arteriole pulse waveform analysis using a fully-automated Doppler optical coherence tomography flowmeter: a pilot study. Transl Vis Sci Technol. 2019;8:13.

182. Martínez A, Sanchez-Salorio M. Predictors for visual field progression and the effects of treatment with dorzolamide $2 \%$ or brinzolamide $1 \%$ each added to timolol $0.5 \%$ in primary open-angle glaucoma. Acta Ophthalmol. 2010;88:541-52.

183. Martínez A, Sánchez-Salorio M. A comparison of the long-term effects of dorzolamide $2 \%$ and brinzolamide $1 \%$, each added to timolol $0.5 \%$, on retrobulbar hemodynamics and intraocular pressure in open-angle glaucoma patients. J Ocul Pharmacol Ther. 2009;25:239-48. 
184. Galose MS, Elsaied HM, Macky TA, Fouad PH. Brinzolamide/timolol versus dorzolamide/timolol fixed combinations: a hospital-based, prospective, randomized study. Indian J Ophthalmol. 2016;64: 127-31.

185. Jaenen N, Baudouin C, Pouliquen P, Manni G, Figueiredo A, Zeyen T. Ocular symptoms and signs with preserved and preservative-free glaucoma medications. Eur J Ophthalmol. 2007;17:341-9.

186. Pisella PJ, Pouliquen P, Baudouin C. Prevalence of ocular symptoms and signs with preserved and preservative free glaucoma medication. $\mathrm{Br} \mathrm{J}$ Ophthalmol. 2002;86:418-23.

187. Tatham AJ, Weinreb RN, Medeiros FA. Strategies for improving early detection of glaucoma: the combined structure-function index. Clin Ophthalmol. 2014;8:611-21.

188. Harasymowycz P, Birt C, Gooi P, et al. Medical management of glaucoma in the 21st century from a Canadian perspective. J Ophthalmol. 2016;2016: 6509809.

189. Laboratories Merck Sharp \& Dohme-Chibret (2009) Cosopt package insert. https://www.accessdata.fda. gov/drugsatfda_docs/label/2010/020869s036lbl. pdf. Accessed 19 Oct 2020.

190. Sousa DC, Leal I, Nascimento N, Marques-Neves C, Tuulonen A, Abegão PL. Use of ocular hypotensive medications in Portugal: PEM Study: a cross-sectional nationwide analysis. J Glaucoma. 2017;26: $571-6$.

191. Holló G, Katsanos A, Konstas AG. Management of exfoliative glaucoma: challenges and solutions. Clin Ophthalmol. 2015;9:907-19.

192. Erb C, Gast U, Schremmer D. German register for glaucoma patients with dry eye. I. Basic outcome with respect to dry eye. Graefes Arch Clin Exp Ophthalmol. 2008;246:1593-601.
193. Baudouin C, Aragona P, Messmer EM, et al. Role of hyperosmolarity in the pathogenesis and management of dry eye disease: proceedings of the OCEAN group meeting. Ocul Surf. 2013;11:246-58.

194. Definition DE. The definition and classification of dry eye disease: report of the definition and classification subcommittee of the international dry eye workshop (2007). Ocul Surf. 2007;5:75-92.

195. Craig JP, Nichols KK, Akpek EK, et al. TFOS DEWS II definition and classification report. Ocul Surf. 2017; 15:276-83.

196. Stewart WC, Stewart JA, Nelson LA. Ocular surface disease in patients with ocular hypertension and glaucoma. Curr Eye Res. 2011;36:391-8.

197. de Jong C, Stolwijk T, Kuppens E, de Keizer R, van Best J. Topical timolol with and without benzalkonium chloride: epithelial permeability and autofluorescence of the cornea in glaucoma. Graefes Arch Clin Exp Ophthalmol. 1994;232:221-4.

198. Ayaki M, Iwasawa A, Inoue Y. Toxicity of antiglaucoma drugs with and without benzalkonium chloride to cultured human corneal endothelial cells. Clin Ophthalmol. 2010;4:1217-22.

199. Kwon J, Heo JH, Kim HM, Song JS. Comparison of cytotoxic effects on rabbit corneal endothelium between preservative-free and preservative-containing dorzolamide/timolol. Korean J Ophthalmol. 2015;29:344-50.

200. Kaarniranta K, Ropo A. Preferences and ease of use of preservative-free IOP-lowering eye drop containers: a comparison of two multi-dose bottles. Clin Invest (Lond). 2018;8:1.

201. URSATEC GmbH | primary packaging with nonairless $3 \mathrm{~K} 囚$ pump system technology. https://www. ursatec.com/en/products/technology/3kr/. Accessed 27 Mar 2020. 